\title{
Analysis of Ballast Transport in the Event of Overflowing of the Drainage System on High Speed Lines
}

\author{
J. Amblard ${ }^{1}$, C. Pams Capoccioni ${ }^{1}$, D. Nivon ${ }^{1}$, L. Mellal ${ }^{1}$ \\ G. De Cesare ${ }^{2}$, T. Ghilardi ${ }^{2}$, M. Jafarnejad ${ }^{2}$ and E. Battisacco ${ }^{2}$ \\ ${ }^{1}$ Project System Engineering, Société Nationale des Chemins de Fer \\ La Plaine Saint-Denis, France \\ ${ }^{2}$ Laboratory of Hydraulic Constructions \\ Ecole Polytechnique Fédérale de Lausanne, Switzerland
}

\begin{abstract}
The transport of ballast caused by the overflowing of longitudinal drains is a prime example of the interactions between the railway track and its environment. In such conditions, water flowing from the platform, along with debris, may drag the ballast off the track foundation. The rate of ballast erosion rises when obstacles are placed along the platform.

To better understand the phenomenon of ballast transport, research was undertaken in collaboration with Ecole Polytechnique Fédérale de Lausanne (EPFL). Systematic tests were performed on a physical model, using a 1:3 scale factor, under both normal and severe operational conditions, as well as in the case of a platform obstructed by obstacles. Numerical simulations were also run to evaluate different optimised configurations for the drainage system of the platform.

The obtained results have improved the understanding of the phenomenon of ballast transport and have made it possible to identify at risk areas where the overflowing may negatively affect the railway traffic.
\end{abstract}

Keywords: ballast transport, natural disaster, risk analysis, drainage overflowing, physical model, railway track structure.

\section{Introduction}

Ballast is an essential component of a railway track structure. The interactions between the ballast and its surrounding environment must be understood so as to assess the potential impact the two have on each other. In particular, only a few studies were carried out on the link between local conditions causing ballast entrainment and the system overflow. The present research project was triggered by a rapid and extreme eventwhich occurred in Sarry in the year 2000.

A severe thunderstorm occurred in Sarry, on the high speed line (HSL) between Paris and Lyon in September 2000. This incident has highlighted the flood risk on 
the platform, with ballast entrainment. The damage to the platform and to the ballast generates a destabilisation of the railroad which could cause a derailment. Figure 1 shows a synoptic of the event.

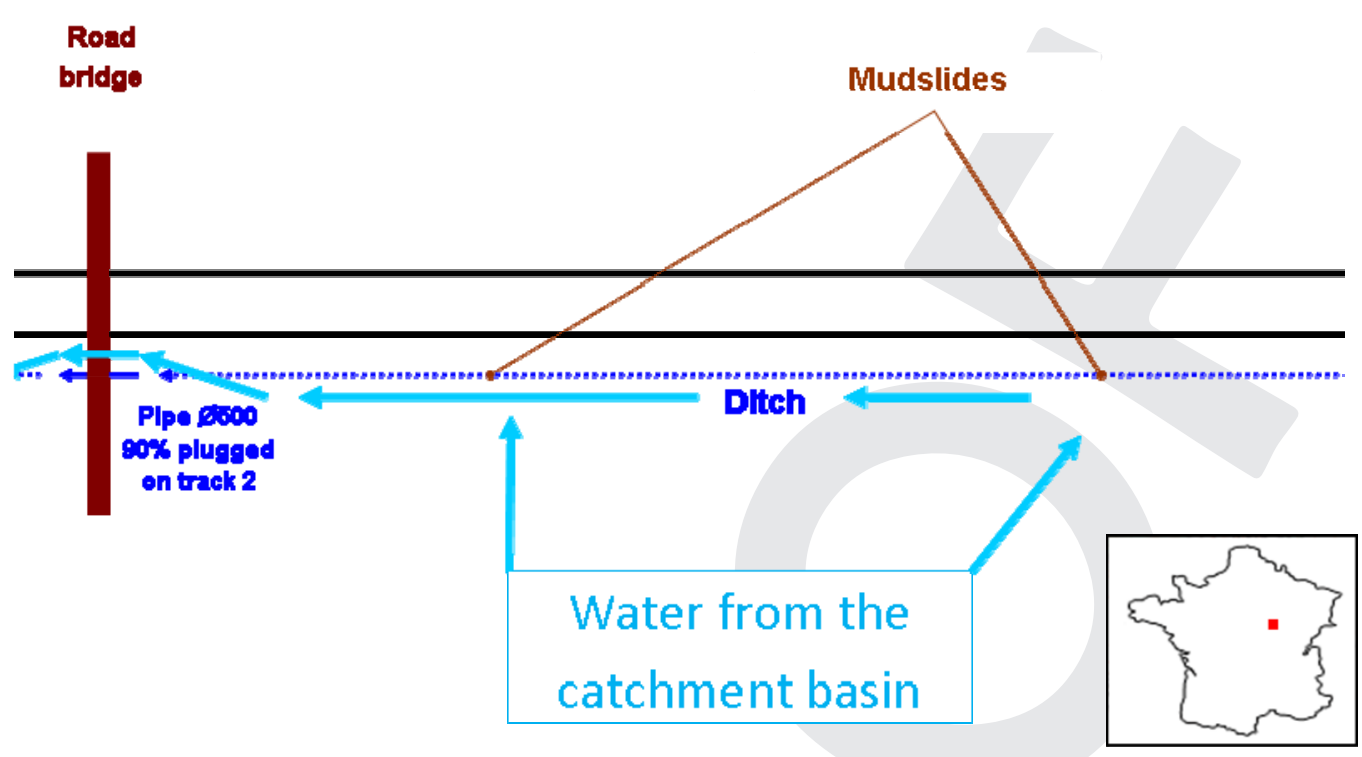

Figure 1: Situation of the incident in Sarry, in September 2000

An extreme rainfall event produced an intense surface runoff that led to mudslides along the cutting of this area on the HSL. Water, mixed with solid materials, flooded the area. As shown in Figure 2, the undersizing of the hydraulic structures caused their overflowing onto the pathway, which finally led to the transportation of ballast far from the track structure.

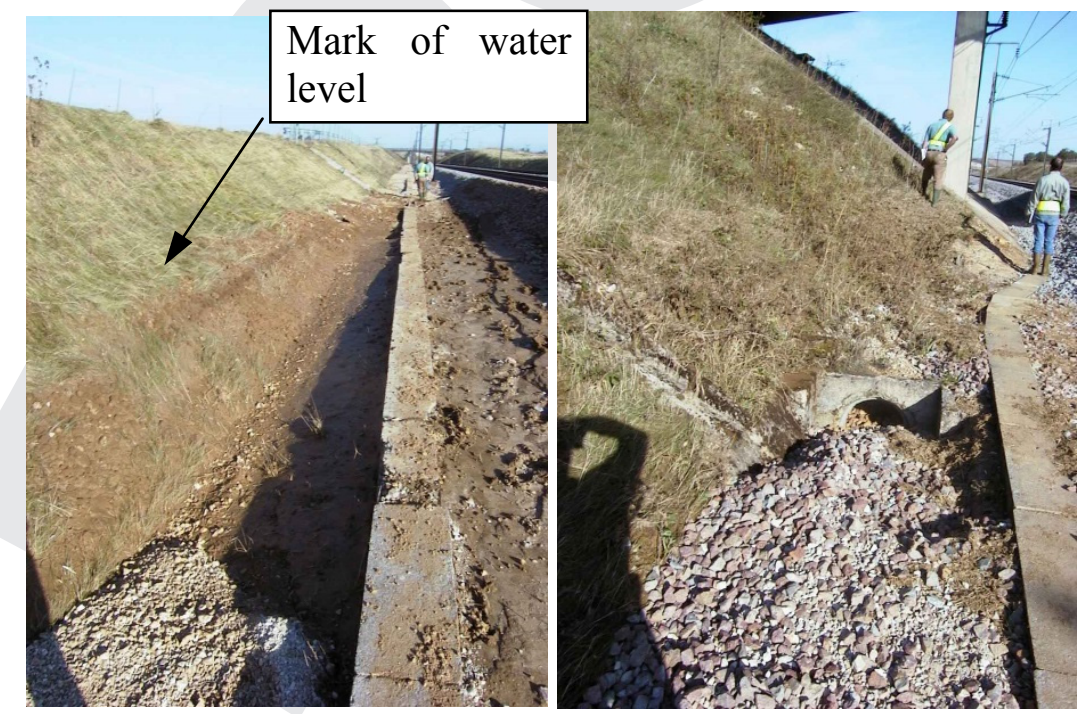

Figure 2: Damages observed aside the track 1 (on the left) and track 2 (on the right)

A short distance downstream, the phenomena was worsened by the blocking of the drainage pipe under a bridge at $164 \mathrm{~km}+591 \mathrm{~km}$ by debris transported by the overland 
flow. The high flow velocity under the bridge, caused by the reduced section of the service pathway, combined with the steep slope (3.5\%), increased the entrainment of the ballast layer. As a result of the elevated position of track 2 compared to track 1, the flow eroded the ballast layer until crossing the border from track 2 to 1 . A train driver reported an unusual shock, which was later proved to be related to track subsidence as a result of the loss of the ballast layer. Consequently, an alert was raised by the maintenance staff and the traffic was interrupted for several hours after.

It was found that the runoff on the platform, usually caused by the overflowing of the drainage system, is the main cause of ballast entrainment. When obstacles, such as drainage manholes, catenary poles or bridge piers, are present along the railroad, the ballast entrainment risk increases drastically (Figure 3).

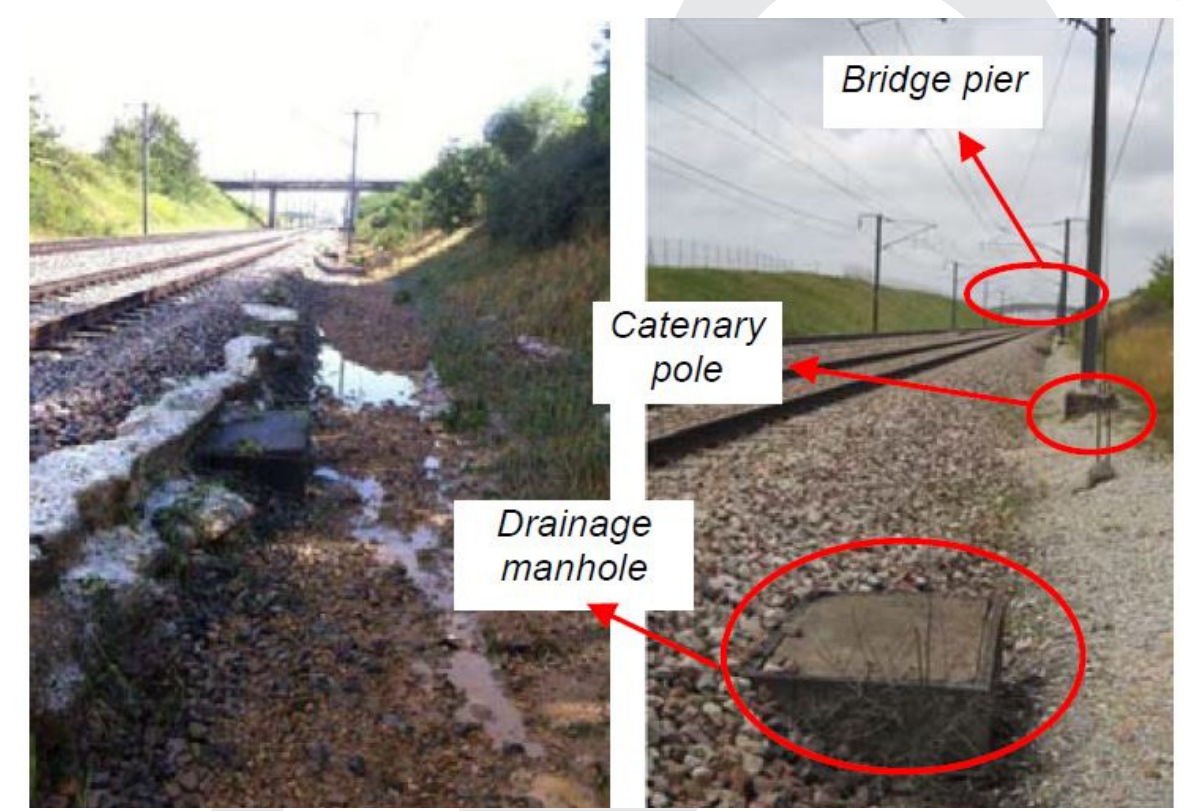

Figure 3 : Left, effect of thunderstorm. Right, common obstacles along the railroad

The problem of ballast entrainment and track failure can be assimilated to the riprap stability issue. The riprap are nowadays widely used to protect bridge abutments, shorelines, and banks, against scour and erosion induced by flowing water or waves.

In fact, as for riprap stability, the slope of the ballast track, the water depth, and the flow velocity, are the fundamental parameters. Several authors have studied the problem of riprap stability [1-3].

The robustness of a particular riprap design can be evaluated by a numerical value for the safety factor. The latter is defined as the ratio of moments resisting particle motion to the moments tending to rotate the particle out of the riprap blanket. The incipient motion condition is represented by a safety factor equal to the unity. It is possible to establish a relation, based on theoretical assumptions, between the riprap safety factor with the magnitude and the flow velocity direction. In particular, close to the riprap, both the angle of the side slope and the angle of repose 
for the riprap play an important role in determining the stability of the bank itself [4].

For the above-mentioned reasons, the problem of ballast entrainment should be considered closer to the riprap failure problem than to a sediment transport issue.

The water flowing along the track exercises some forces on the ballast toe, which may destabilise the track. Another issue may come from the water inside the track that could increase the ballast failure risk. However, this research focuses only on the ballast entrainment as a result of the water flowing along of the track.

So far, most studies have only focused on the stability in the absence of obstacles along the pathway $[2,3]$. In the present case, the erosion occurring in the absence of obstacles for several longitudinal slopes is compared to the erosion caused by the presence of obstacles, which is quite common along railway tracks. The comparison of ballast entrainment in the presence and absence of obstacles allowed us to define an Obstacle Impact Coefficient ( $c f .3 .3 .2$ ). To the best of the author's knowledge, this specific problem has not been investigated so far.

For HSLs, the potential impact arising from ballast entrainment is more important than for 'classic' lines as a result of the combination of high-speed with high-rates of usage. Therefore, the consequence of an incident involving HSLs would be significant [5].

The Société Nationale des Chemins de Fer (SNCF), responsible for the maintenance of rail infrastructure in France, outlined a wide range of initiatives to define the "Sarry risk" and to improve the understanding of ballast entrainment. Among the mitigation measurements proposed by SNCF, different scales of intervention were taken into account, from monitoring to important construction works in the areas considered of "high risk". The identification of the "Sarry risk" segments and the initial solution to the problem are presented in Section 2.

One of these measures was the development of a research project carried out on a physical model at 1:3 scale and the numerical optimisation of the pathway drainage system. The goal of the research was to provide novel scientific achievements which would help to give a better understanding of the hydraulic risks on HSLs. The main investigations and results are presented in this paper, in Section 3 and 4.

\section{2 "Sarry risk" areas: identification and urgent measures}

SNCF outlined a wide range of initiatives to reduce the vulnerability of the railway infrastructure caused by the overflowing of the adjacent hydraulic structures, the so called "Sarry risk" [6-9].

\subsection{Inventory and ranking of the "Sarry risk" areas on HSLs}

The first measure undertaken was to initiate a campaign of visits by experts to the oldest HSLs in order to identify the sites at risk of overflowing. The aim was mainly to evaluate the condition of the hydraulic structures along the HSLs. The "Sarry 
risk" is closely related to the design rules adopted during the railway line construction and to the potential changes to the drainage system. For each hydraulic structure, the hydraulic capacity was assessed with the Manning-Strickler Equation [10] providing a direct relationship between velocity, water depth, and slope. This value was then compared with the design discharge of the hydraulic structure (ten-year return period for longitudinal hydraulic structures) obtained with the Rational Equation (1) where $\mathrm{Q}=$ design discharge $\left(\mathrm{L}^{3} / \mathrm{T}\right), \mathrm{C}_{\mathrm{u}}=$ units conversion coefficient, $\mathrm{C}=$ runoff coefficient (dimensionless), $\mathrm{i}=$ design rainfall intensity $(\mathrm{L} / \mathrm{T})$, and $\mathrm{A}=$ watershed drainage area $\left(\mathrm{L}^{2}\right)$.

$$
Q=C_{u} C i A
$$

The rational method is used if the size of the drainage basin is under $1 \mathrm{~km}^{2}$. The method is described in most standard textbooks [11].

The hydraulic structures were classified considering the vulnerability of the rail traffic in case of the drainage system overflowing. For each railway line, three categories of risk were provided:

- Category 1: Sites with an insufficient capacity and a prejudicial risk for rail traffic in case of a rainstorm event below the return period used in the design at the time of the creation of the line ;

- Category 2: Sites with an insufficient hydraulic capacity but a non-prejudicial risk for rail traffic in case of a rainstorm event up to the return period used at the time of the creation of the line ;

- Category 3: Sites potentially vulnerable but with a non-prejudicial risk for rail traffic in case of a rainstorm event up to the return period used at the time of the creation of the line.

The results clearly revealed that the number of sites classified as "high-risk areas" (in category 1) is higher for old HSLs and decreases for railway lines built more recently, thanks to the improvements made to the design standards since the ParisLyon HSL was completed in 1981. Therefore, the campaign of visits was realised only for the four oldest HSLs. The years of construction of the evaluated and nonevaluated HSLs are given in Table 1.

\begin{tabular}{|c|c|c|}
\hline & HSL & $\begin{array}{c}\text { Year of } \\
\text { construction }\end{array}$ \\
\hline Line evaluated & Paris-Lyon (LN1) & 1978 \\
\hline Line evaluated & Atlantic (LN2) & 1983 \\
\hline Line evaluated & North / Lyon-Valence (LN3 / LN4) & 1989 \\
\hline Line non-evaluated & Mediterranean (LN5) & 1996 \\
\hline Line non-evaluated & East (LN6) & 1998 \\
\hline Line non-evaluated & Rhine - Rhône (LN7) & 2011 \\
\hline
\end{tabular}

Table 1: HSLs considered for the inventory and the ranking of the "Sarry risk" areas 
The technical-reference-guidebook, related to the construction works of an HSL, details the design rules for civil engineering structures, such as hydraulic constructions, for both maintenance and safety. After the construction of the new HSLs, measures have been initiated in order to adapt and to modify this guidebook and the current version takes into account the "Sarry risk" issue in order to reduce the overflowing risk onto the pathway.

Nevertheless, the behaviour of drainage systems must be examined for extreme flow (1.8*Design flow), especially where singularities, such as culverts crossing road or bridge foundations, are present.

\subsection{Urgent measures: decreasing the probability of overflowing on high-risk areas}

In areas classified as "high-risk", rehabilitation works are undertaken to reduce the risk. Hydraulic works, such as the construction of retention basins and the resizing of hydraulic structures, are undertaken after completing a precise risk analysis of the area. The criteria normally used to characterise the flow, either in a river, pipe or channel, are the water level and the flow velocity. These values are then characterised in terms of the energy of the flow and the possibility of erosion that may occur.

In order to evaluate the risk of ballast entrainment, it is particularly important to calculate the forces acting on the ballast toe, which are, among other considerations, directly related to the water depth and to the longitudinal and lateral slope of the pathway. This calculation can be done by means of a one-dimensional hydraulic model calculating the flooded area, the water level, and of the flow velocity anywhere in the area. To build a suitable model, at least ten cross-sections are needed. For each "high risk" region highlighted by a preliminary work (as explained in Subsection 2.1), the discharges for a given return period event were calculated using the one-dimensional hydraulic model. Figure 4 (see below) shows a crosssection for a 10 years return period event just upstream a road bridge.

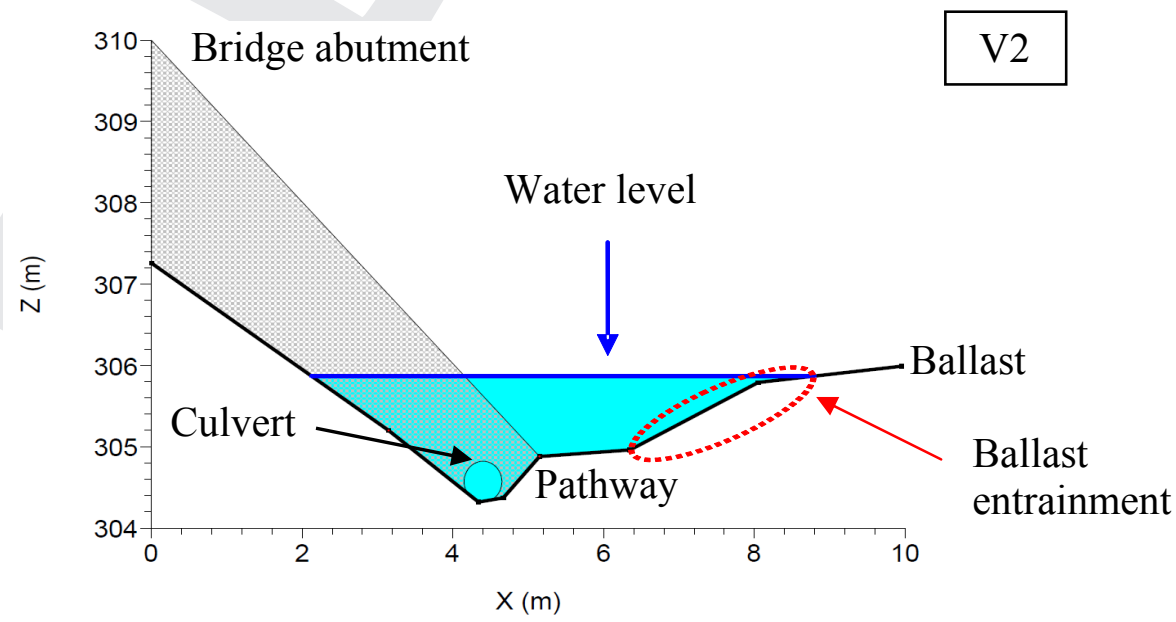

Figure 4: Cross-section obtained with a hydraulic numerical model for a 10-year return period event (case of the road bridge in Sarry) 
The hydraulic assessment based on the mathematical model allows the precise identification of high-risk areas. In these areas, the new design standards are applied in order to improve the hydraulic structures and thus reduce/eliminate the pathway flooding risk. During the last ten years, construction works have been carried out on several "high risk" points in order to improve the hydraulic structures efficiency, as shown in Figure 5.
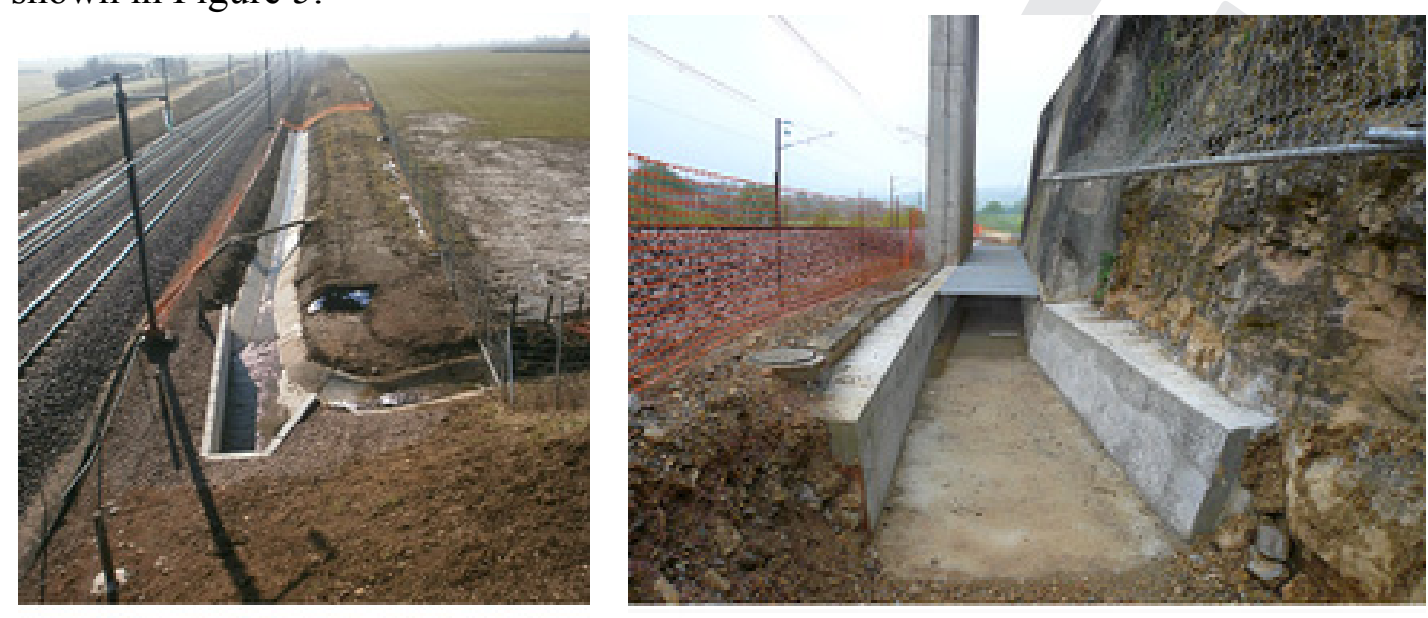

Figure 5: Pictures of rehabilitation works on the outskirts of a HSL

\section{Study of ballast entrainment on a physical model}

\subsection{Phenomenological study on a physical model}

The analysis mentioned so far allows one to locate and to partially solve the overflowing of the drainage system. However, field observations clearly indicate that the impact of the flow on the ballast also depends on the local configuration. The longitudinal slope, the pathway material, and the presence of obstacles such as bridge piers, catenary poles, and manholes along the track have a clear impact on the "Sarry risk". In particular, they influence the amount of ballast entrained by the flow the region where the ballast is entrained, and the discharge for which this occurs.

Nowadays numerical models, as sophisticated as they may be, are not able to supply reliable answers to these questions [1,2] involving sediment transport phenomena and lateral erosion. Thus, a physical scale model has been built in collaboration with EPFL in order to study the phenomenon. The experimental setup is presented in Section 3.2 and the results in Section 3.3.

These hazard events normally have a short duration (20 minutes to one hour) and thus it is really difficult for the maintenance staff to reach the site and to acquire onsitu measurements while the event is still on going. Moreover, water level traces are immediately lost as a result of the recovery works done for assuring train circulation. Therefore, discharge and water level measurements needed to calibrate the numerical models for critical events, as in the "Sarry risk" case, are often missing. Considering the lack of available data, the infrastructure owners - Réseau Ferré de France (RFF) - suggested the creation of a physical model in order to better define: 
- The phenomena involved in overflowing drainage structures $[12,13]$;

- The criteria for ballast entrainment (water depth/velocities) in order to define the risk;

- The impact of 3 types of obstacles (i.e. a catenary pole support, a bridge abutment, and a manhole).

This research project, called "Impact sur le Ballast des Eaux de Ruissellement" (IBER) [13] - which translates as "Runoff water Impact on the Ballast" - was financed by RFF and managed by the Engineering Division of the SNCF.

\subsection{Experimental setup and procedure}

\subsubsection{Experimental setup}

The cross-section presented in Figure 6 is reproduced on the physical model $[15,16]$, built on a geometric scale of 1:3 at the Laboratory of Hydraulic Construction LCH of EPFL, is $10 \mathrm{~m}$ long and $1.5 \mathrm{~m}$ wide (Figure 7). It is operated on Froude similarity, which means respecting the conservation of the inertial to gravity forces ratio.

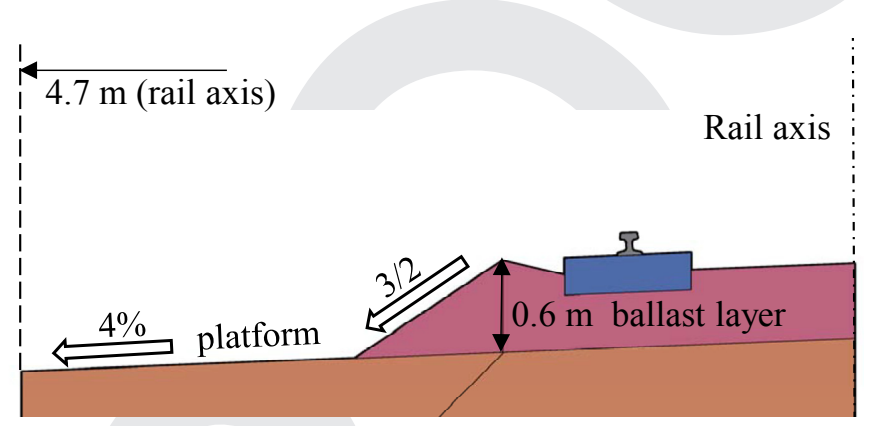

Figure 6: Prototype section as modelled in the laboratory
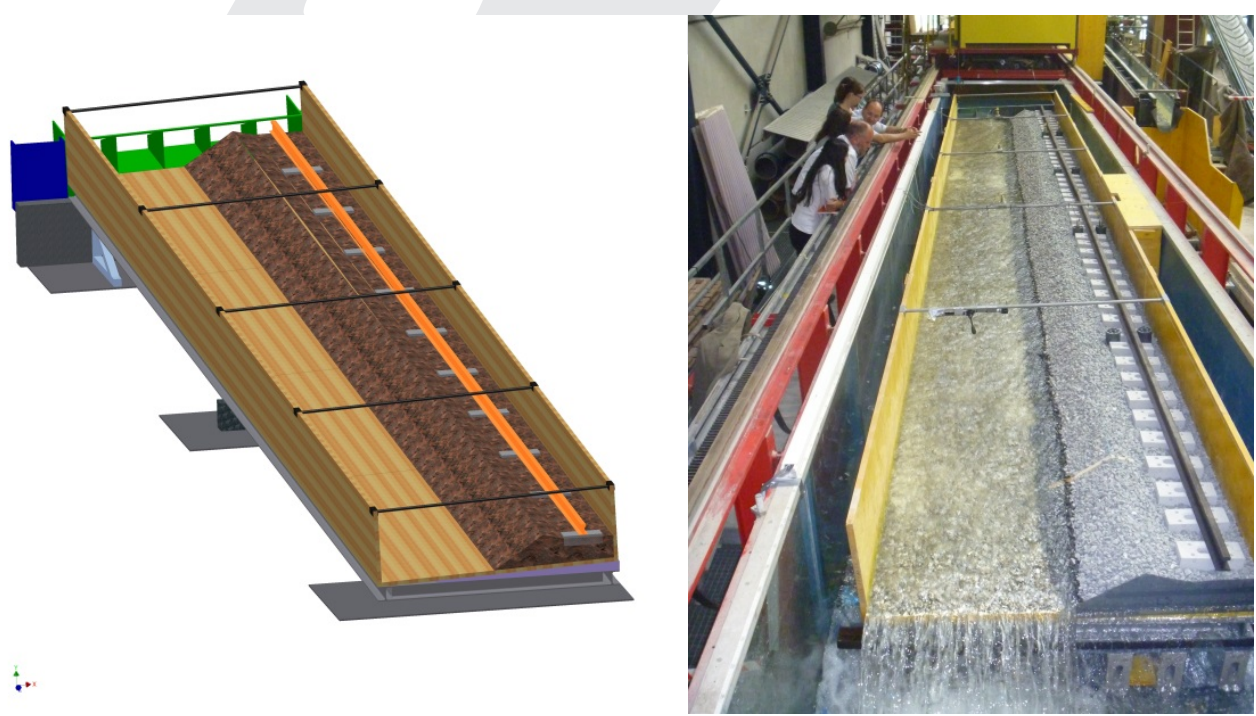

Figure 7: Physical model at a 1/3 scale with water flowing without any obstacle 
The sediment transport similarity is guaranteed by the respect of the Shields criteria for ballast entrainment [13]. The erosion of the platform is not analysed in this study. Thus, the mobile ballast is placed over a fixed platform. In order to reproduce the platform, the scaled grain size distribution was fixed by SNCF. The code NF EN 13450 is used to define the grain size in order to reproduce the ballast used in French railways. As a result of the small scale (1:3), the scaling of the grains corresponds to the geometrical scale. The grain diameter used for the fixed platform varies from between $2 \mathrm{~mm}$ and $8 \mathrm{~mm}$ (scaled dimensions), thus presenting a uniform distribution. Angular grains with a mean diameter of $15 \mathrm{~mm}$ (scaled dimensions) where used; this corresponds to a prototype mean diameter of $44 \mathrm{~mm}$. The profile presented in Figure 6 was reproduced in the laboratory experiments. In order to build the ballast track, sediments were initially vibrated in order to reproduce a compaction similar to that encountered on the prototype [17]. For visual reasons, one rail was also placed on top of the ballast.

Water discharge, fed constantly by the closed general pumping system of the laboratory, is measured by an electromagnetic flow-meter $( \pm 21 / \mathrm{s})$.

Water levels are measured using ultrasonic probes regularly distributed along the model. The ultrasonic probes provide an accuracy of $1 \mathrm{~mm}$ for the laboratory measurements.

During the first series of experiments ( $c f$. Section 3.2.2), the flow velocity was also measured by means of a micro propeller $( \pm 0.6-40 \mathrm{~m} / \mathrm{s}$ fluid scale) on a vertical profile.

\subsubsection{Experimental procedure}

Tests were carried out for several configurations of longitudinal slopes, discharges and obstacle configuration.

The tests were divided into three series. During the first test series [14], the tested longitudinal slope of the platform lay between 0.5 and $3.5 \%$, with and without obstacles along the track. The influence of one obstacle per time was evaluated (Sections 3.3.1 and 3.3.2). The obstacles used are a manhole, a catenary pole, and a bridge abutment. These obstacles reduce the flow section and modify the flow pattern, influencing the ballast entrainment. The used obstacles are presented in Figure 8 .
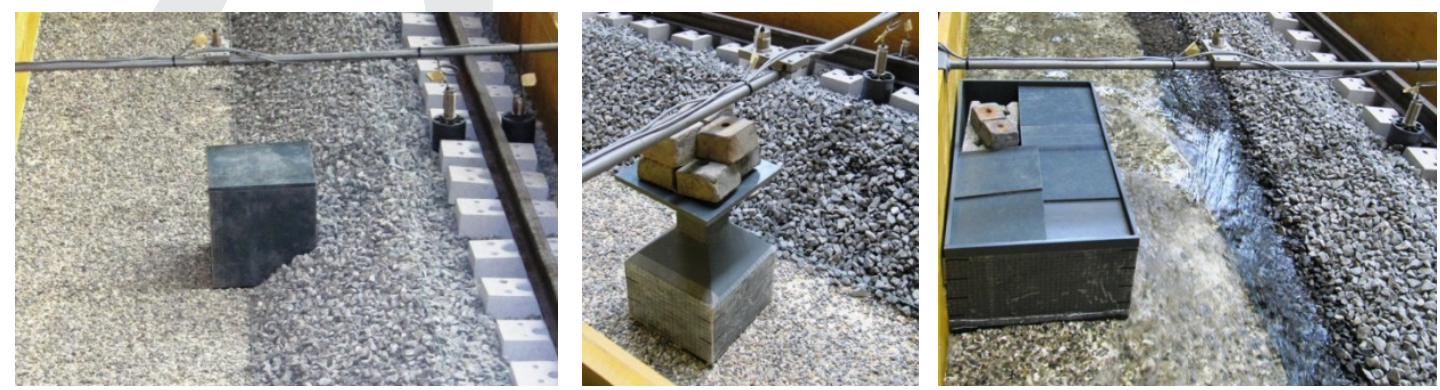

Figure 8: Picture of the used obstacles and their position on the platform. Left: manhole; centre: catenary pole; right: bridge pier 
According to the single obstacle results, the second phase [18] studied the combined impact of two obstacles (Section 3.3.3). Tests with two obstacles were carried out for two platform slopes $(0.65 \%$ and $3 \%)$. Two distances between obstacles have been used ( $3 \mathrm{~m}$ and $4.5 \mathrm{~m}$ on prototype) and were decided according to the zone of maximum erosion caused by the upstream obstacle alone.

In the third phase, the effect of a train transit was tested by means of a vibrator machine installed on the model (Section 3.3.4).

During the experiments, the discharge is increased by steps of about $15-20 \mathrm{l} / \mathrm{s}$ during the test. The measurements of water depth and velocity started once the incipient motion of the ballast (beginning of movement of some grains) was visually observed on the model. Each three minutes, the eroded ballast is grouped and weighted and then the discharge is increased. The same procedure is repeated until either the water depth reaches the ballast crest or, as a result of the ballast erosion and further entrainment on the platform, the track fails. The above mentioned process permits one to evaluate the intensity of the ballast entrainment in different operation conditions.

A series of systematic tests were performed for 7 longitudinal slopes ranging between $0.5 \%$ and $3.5 \%$ which respectively represent normal and severe conditions possible along the HSLs in France. The first series of tests, reproducing the case of an unobstructed platform, was useful in understanding the flow behaviour and the ballast entrainment.

\subsection{Results}

\subsubsection{Absence of obstacles}

In order to obtain reference values, experiments were carried out in the absence of obstacles. For each slope, the water-ballast interaction was analysed, indicating the existence of clearly delimited solid transport classes, independent from the slopes. Four classes of transport were defined using a limit-discharge criterion, as shown in Table 2.

\begin{tabular}{|c|}
\hline Transport class and solid discharge limit \\
$\begin{array}{c}\text { No solid transport } \\
\text { No movement is observed }\end{array}$ \\
\hline $\begin{array}{c}\text { Initiation of transport } \\
\text { Movement of few grains of ballast is identified. The } \\
\text { transport can be visually identified only on the ballast } \\
\text { toe. }\end{array}$ \\
\hline \hline $\begin{array}{c}\text { Linear transport } \\
\text { An important amount of ballast is entrained, but no } \\
\text { local rupture can be identified. }\end{array}$ \\
$\begin{array}{c}\text { Intense ballast transport resulting in structural failure } \\
\text { Rupture of the ballast track, with sudden increase in } \\
\text { sediment transport. }\end{array}$ \\
Limit
\end{tabular}

Table 2: The definition of the solid transport and associated limits 
The limit discharge distinguishes two classes of sediment transport. The classes are limited based on quantified criteria (entrainment of the ballast per meter of length of the platform in $\mathrm{kg} / \mathrm{min} / \mathrm{m}$ ), which cannot be reported in the present study. A description of the observed state of the ballast is instead reported in the table.

The data analysis pointed out that the sediment transport classes are delimited by power laws that are a function of the longitudinal slope of the platform and of the water depth. The link with the flow velocity was less clear, but existent. Since, according to the Manning-Strickler Equation [10], a direct relationship exists between the velocity, the water depth, and the slope, the equation of the limits can also be expressed in terms of flow discharge. Figure 9 gives a schematic representation of the ballast entrainment limits as a function of the platform slope and the water depth. A similar representation can be obtained as a function of the slope and the water discharge per unit width of the platform. Equations based on the water discharge are less precise, as a result of the abovementioned not clearly defining a link between the flow velocity and sediment transport classes. However, the water discharge per unit width of platform is not influenced by the presence of the obstacles and can also be more easily estimated based on precipitation events. It has thus been chosen to analyse the impact of the presence of the obstacle along the ballast track based on the water discharge per unit of width.

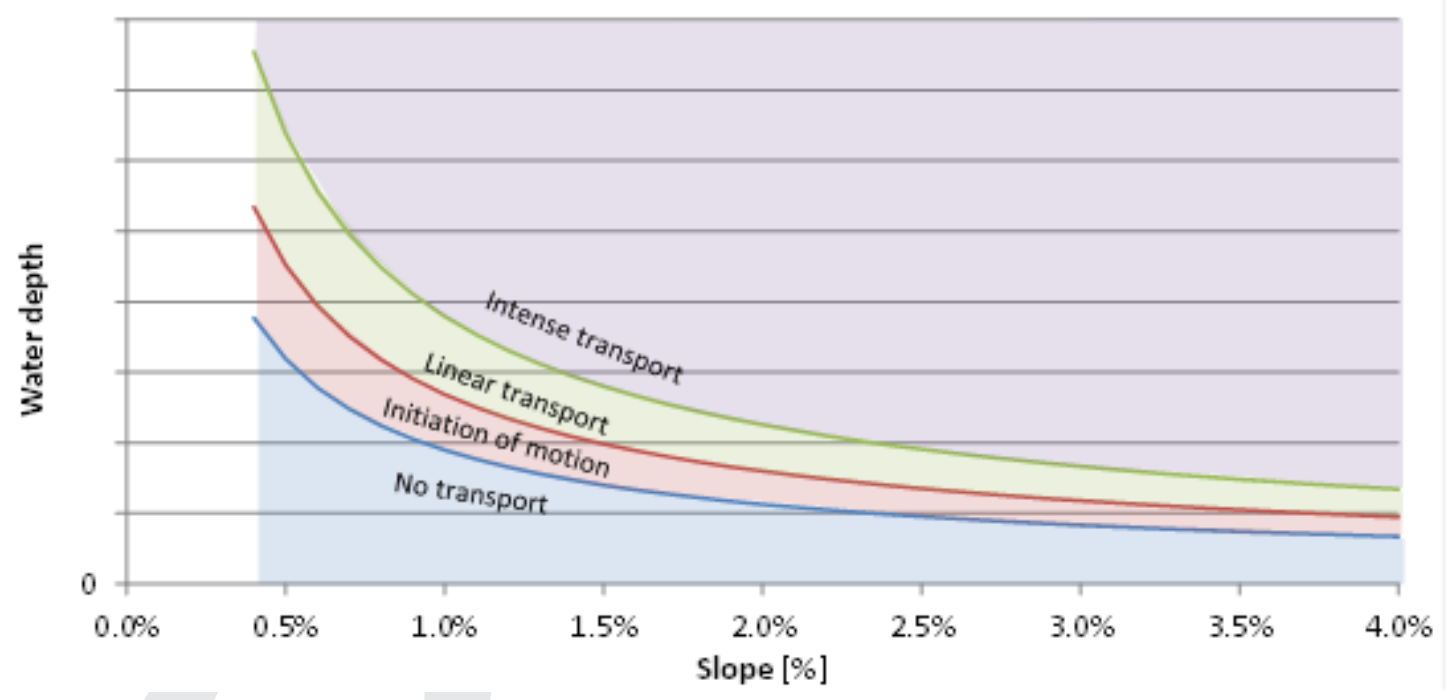

Figure 9: Representation of the sediment transport classes and limits as a function of the slope and the water depth

The results in the absence of obstacles show that:

- Unique fixed criteria of water height and velocity are less relevant regardless of the slope; both the flow velocity and water depth should not to be exceeded along the track but must clearly be linked both to the platform slope and to the presence of obstacles ( $c f$. Section 3.3.2) 
- For low gradient slopes, purely empirical criteria used until now are too restrictive. Optimisation during planning and design and rehabilitation works are then possible;

For higher gradient slopes, ballast transport may begin even with only a few centimetres of water depth.

\subsubsection{Impact of a single obstacle}

The obstacles presented in Figure 8 were used in order to analyse their individual and localised impacts on the ballast entrainment. As a result of the presence of the obstacles, the water depth and the flow velocity were no longer uniform. Thus, the classes of sediment transport defined in Table 3 can no longer be identified as a function of these parameters. For this reason, as previously mentioned, the limits of the classes were defined as a function of the platform longitudinal slope and of the unit discharge.

The presence of an obstacle induces flow regime modifications, which produce backwater curve effects or local acceleration. In the presence of obstacles, the identification of the transport class is less evident than with a mostly uniform flow. It is, however, possible to identify obstacle-impact-coefficient (OIC) for each obstacle and slope, in order to evaluate the impact caused by the obstacle with respect to the case without obstacles on the same slope and discharge. The OIC represents the ratio between the limit discharge in the absence of obstacles and the limit discharge in the presence of the obstacle (Figure 12).

A value of $\mathrm{OIC}>1$ indicates that the obstacle increases ballast entrainment. On the other hand, when OIC is $<1$ the obstacle has a stabilising effect on the ballast.

For low gradient slopes $(0.5 \%)$, the presence of a manhole (Figure 10) increases the ballast entrainment with respect to the reference case without obstacles. However, for higher longitudinal slopes (3.5\%), this same obstacle, instead, plays a stabilising role, as a result of the backwater effect stabilising a part of the ballast track upstream of the manhole. On a smaller slope, since there is practically no ballast entrainment without obstacles, the presence of a manhole does not help stabilising the ballast upstream, but does instead cause an increased erosion downstream, as a result of the flow divergence.

Regardless of the slope, the presence of a catenary pole increases the ballast transport. Nevertheless, its impact decreases for a higher gradient slope.

In the same way, the bridge abutment has a negative effect on the ballast stability. Figure 11 shows the impact produced by this obstacle on the scaled model. This bridge abutment produces the highest OIC. Table 3 summarises the effects du the different obstacles related to tested slope. 


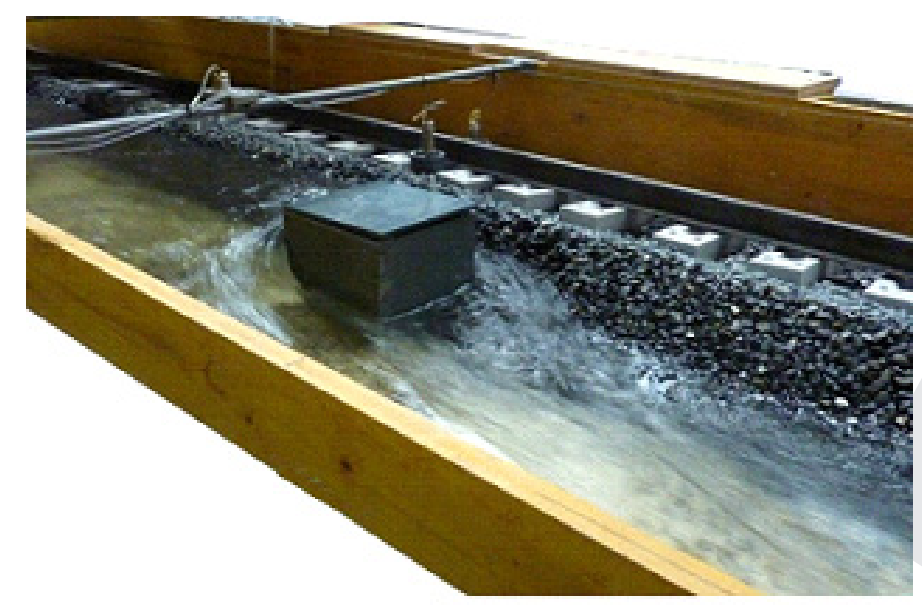

Figure 10: View of the flow around the manhole with an upstream backwater curve

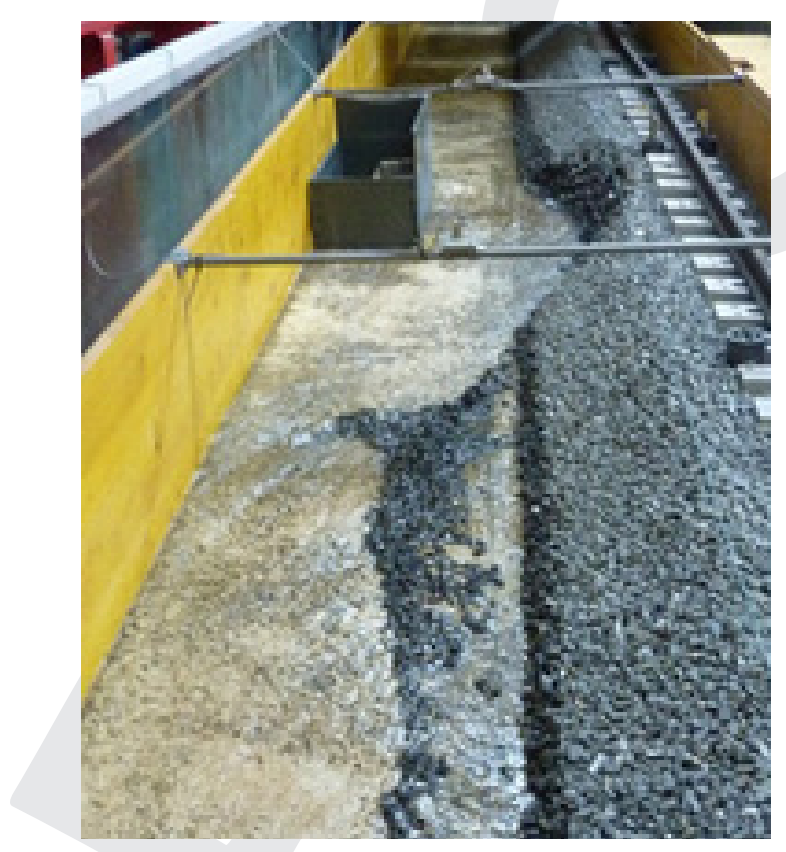

Figure 11: Impact on the ballast of runoff through the reduced section of a road bridge abutment

\begin{tabular}{|c|c|c|}
\hline & Low slopes (0,5\%) & High slopes (3,5\%) \\
\hline \hline Manhole & Increasing impact & Stabilising role \\
\hline \hline Catenary pole & High increasing impact & Low increasing impact \\
\hline \hline Bridge abutment & $\begin{array}{r}\text { Constant increasing impact regardless of the slope } \\
\text { (the most critical obstacle) }\end{array}$ \\
\hline
\end{tabular}

Table 3: Definition of the impact of the obstacles on the ballast transport in comparison with the case without obstacles 


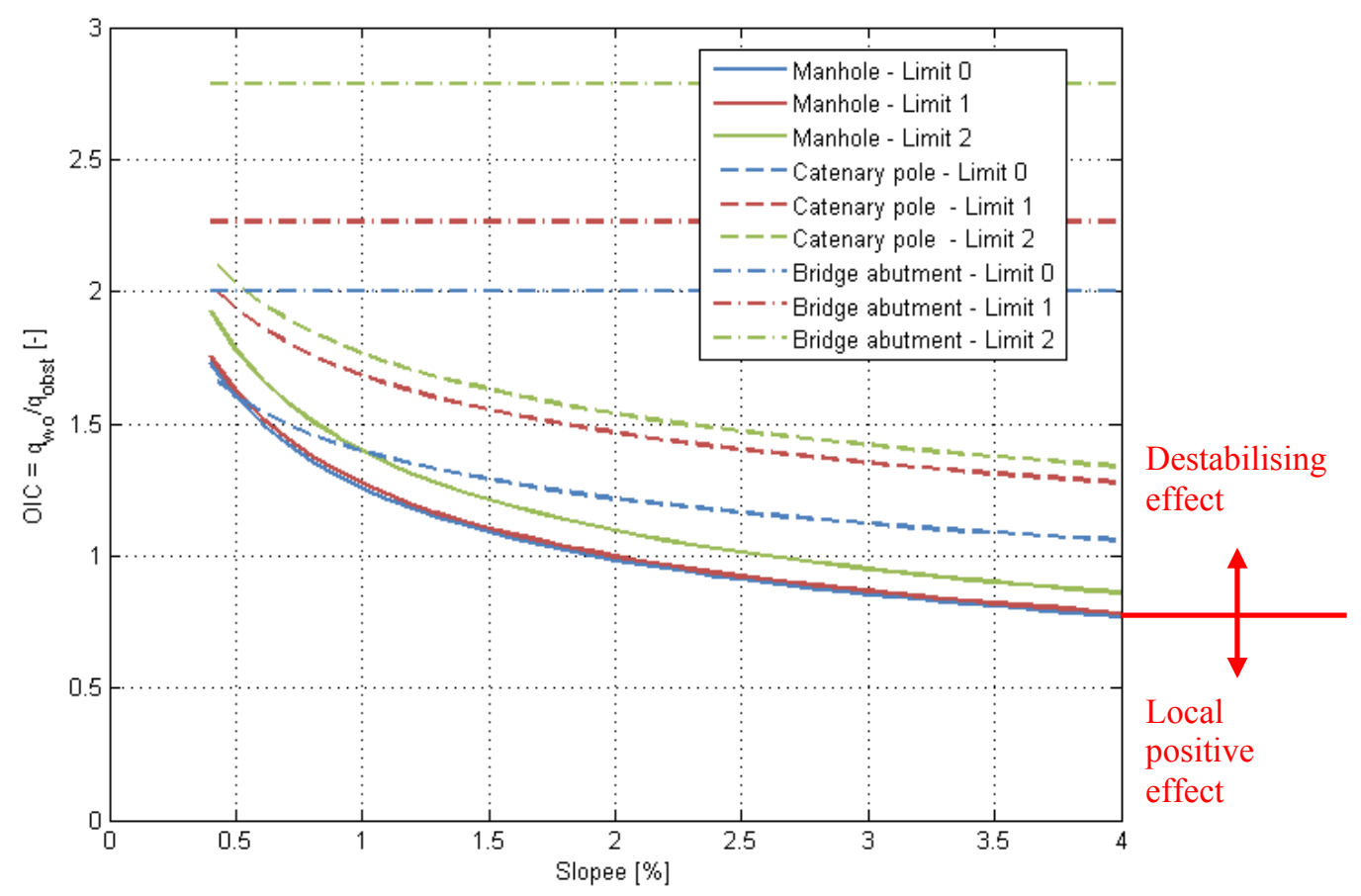

Figure 12: Obstacle-impact-coefficient (OIC), defined as the ratio between the limit discharge without obstacles to the limit discharge with obstacles

\subsubsection{Interactions between two obstacles}

In real life, a succession of obstacles reducing the flow section is present along the railways. It was thus decided to analyse the interactions between two obstacles. The number of possible combination of obstacles, distances, and slopes is huge. This series of tests supply only initial information about the interactions between the obstacles. Further experiments are needed in order to fully optimise the position and interactions between the obstacles along the track.

The combination of two obstacles (i.e. catenary pole, manholes, and bridge abutments) is tested on the scale model. The two tested distances between the obstacles were of $3 \mathrm{~m}$ and $4.5 \mathrm{~m}$ prototype. These distances were chosen based on the observed erosions around the individual obstacles. Again, tests at low slope $(0.65 \%)$ as well as steep slope $(3 \%)$ were performed.

Considering the stabilising effect shown by the manhole alone, this obstacle has been tested only downstream of the first obstacle. The stabilising effect on steep slopes demonstrated in the first test series, with single obstacles, has also been confirmed with the two other obstacles (i.e. catenary pole and bridge piers).

Passing over the entire possible discharge range, it was confirmed that the manhole has no negative impact on the ballast stability for a low flow. 
Figure 13 shows how the erosion process started by the flow in the presence of the manhole placed $3 \mathrm{~m}, 4.5 \mathrm{~m}$, respectively, downstream. The downstream obstacle influences the flow and water level, increasing the water depth and thus reducing the flow velocity, which is mainly responsible for the destabilisation of the ballast layer.
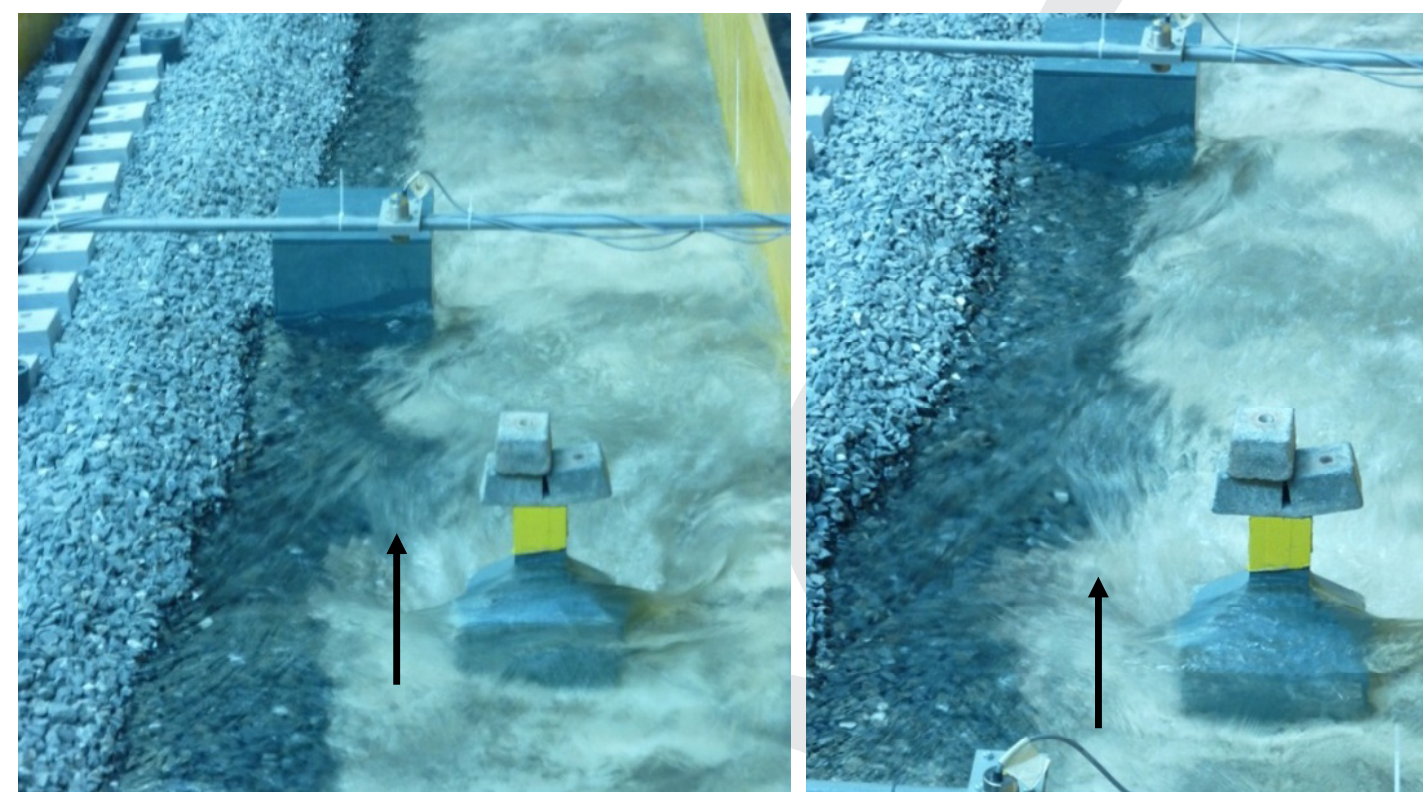

Figure 13: Flow between obstacles (catenary pole upstream and manhole downstream) for a slope of $0.65 \%$ and a specific discharge of $0.63 \mathrm{~m}^{2} / \mathrm{s}$, distance of $3.0 \mathrm{~m}$ (left) and $4.5 \mathrm{~m}$ (right)

The tests demonstrated equally that, even in the case of the steep slope $(3 \%)$, the interaction between obstacles does not have an influence on the erosion process; the distance between the obstacles, as well, has only limited influence on the erosion.

As a general conclusion, it is possible to say that obstacles closer to each other reduce the propagation of the erosion process. On the other hand, for larger distances between obstacles, the ballast particles are more likely to be transported in the flow.

The results also highlight the influence of the slope, the steeper the slope the larger the erosion of the ballast. These general conclusions are in principle not valid for all the tested combinations, in fact, each combination shows a specific behaviour that needs to be investigated in more detail.

The results show that the combination of slope, distance between obstacles, and type of obstacle, create different situations: increased stability, increased erosion or no impact for the ballast layer.

In general, manholes downstream contribute to stabilise the ballast and the effect is more marked for low slopes where the generated local flow velocity reduction has a higher protection effect on the ballast. Considering the combination of catenary pole upstream and bridge pile downstream, the main influence comes from the discharge. Higher flow discharges enhance the erosion process around the obstacle 
downstream. Concluding, bridge piles should be protected locally against erosion when situated downstream of catenary poles whatever the slope is.

\subsubsection{Tests with vibrations (without obstacles)}

For the tests simulating the passage of a train, an electromechanical vibrator has been installed on a double rail representing the track (see Figure 14). The vibrator (Brand ACBMV, type MVSI 10/1400) weights $78 \mathrm{~kg}$, works at a frequency of 60 $\mathrm{Hz}$, with the mass eccentricity adjusted at $7 \%$, the centrifugal force is $1018 \mathrm{~N}$ leading to a work momentum of some $18 \mathrm{Nm}$.

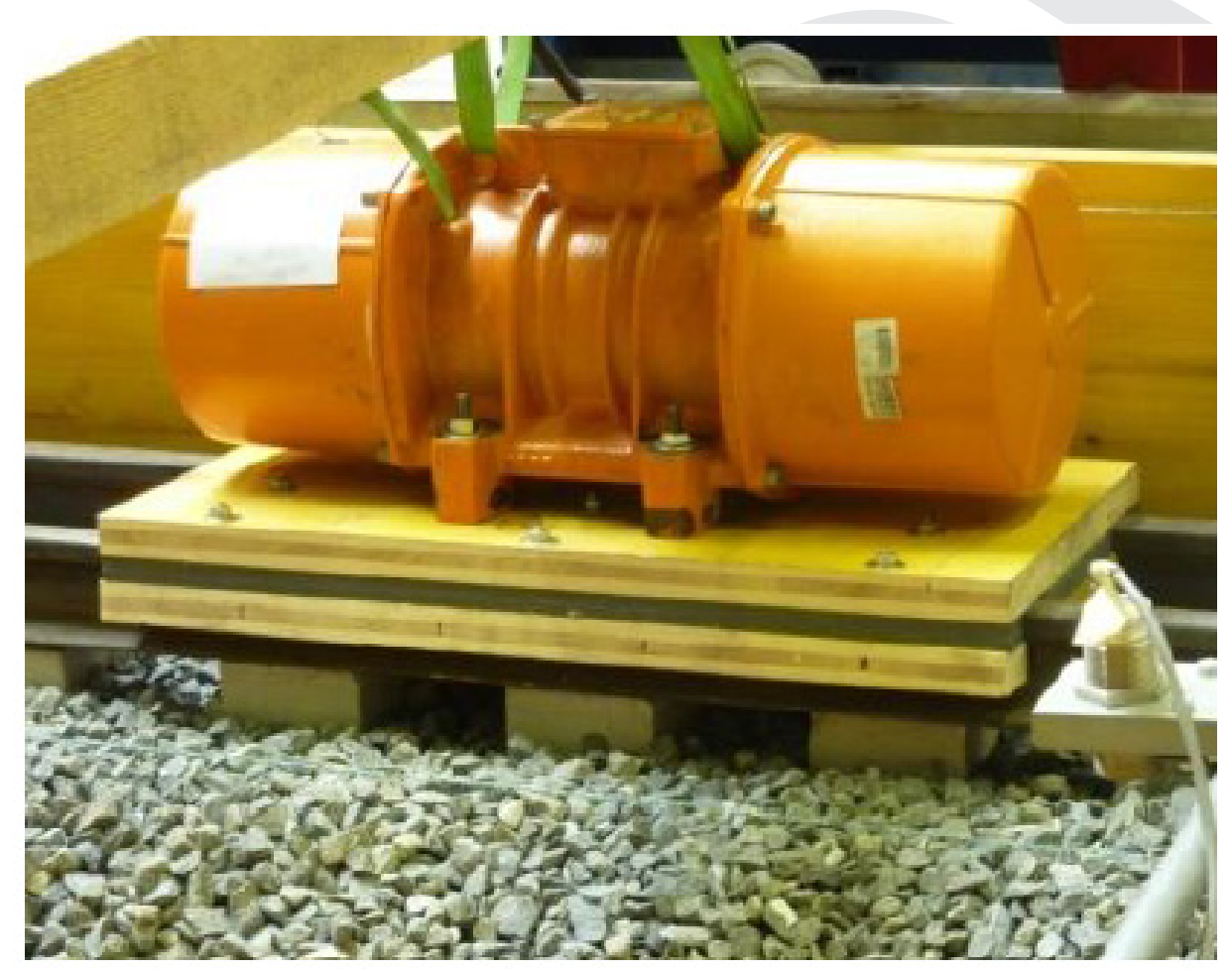

Figure 14: Physical model modified for the tests with vibrations

A series of tests with vibration were made in order to consider the impact of a train passing on the rails with water flowing along the track (see Figure 15). It was observed that train vibrations accentuate the beginning of the ballast mobilisation. The tests were made with a low $(0.65 \%)$ and a steep $(3.0 \%)$ slope on the scale model. The vibration persisted for 2 minutes for every evaluated discharge. No obstacles were placed along the track during the test. The vibration produced by the machine is equal to $60 \mathrm{~Hz}$. In Figure 15 it is noticeable that, as a result of the vibration, the ballast toe has slightly lost its integrity. Nevertheless, the ballast is still stable and the total eroded material remains negligible.

For the steep slope, the toe of the ballast layer is no longer regular at the end of the test. Nevertheless, there is no significant difference between the ballast toe shape in both cases with and without vibrations. 

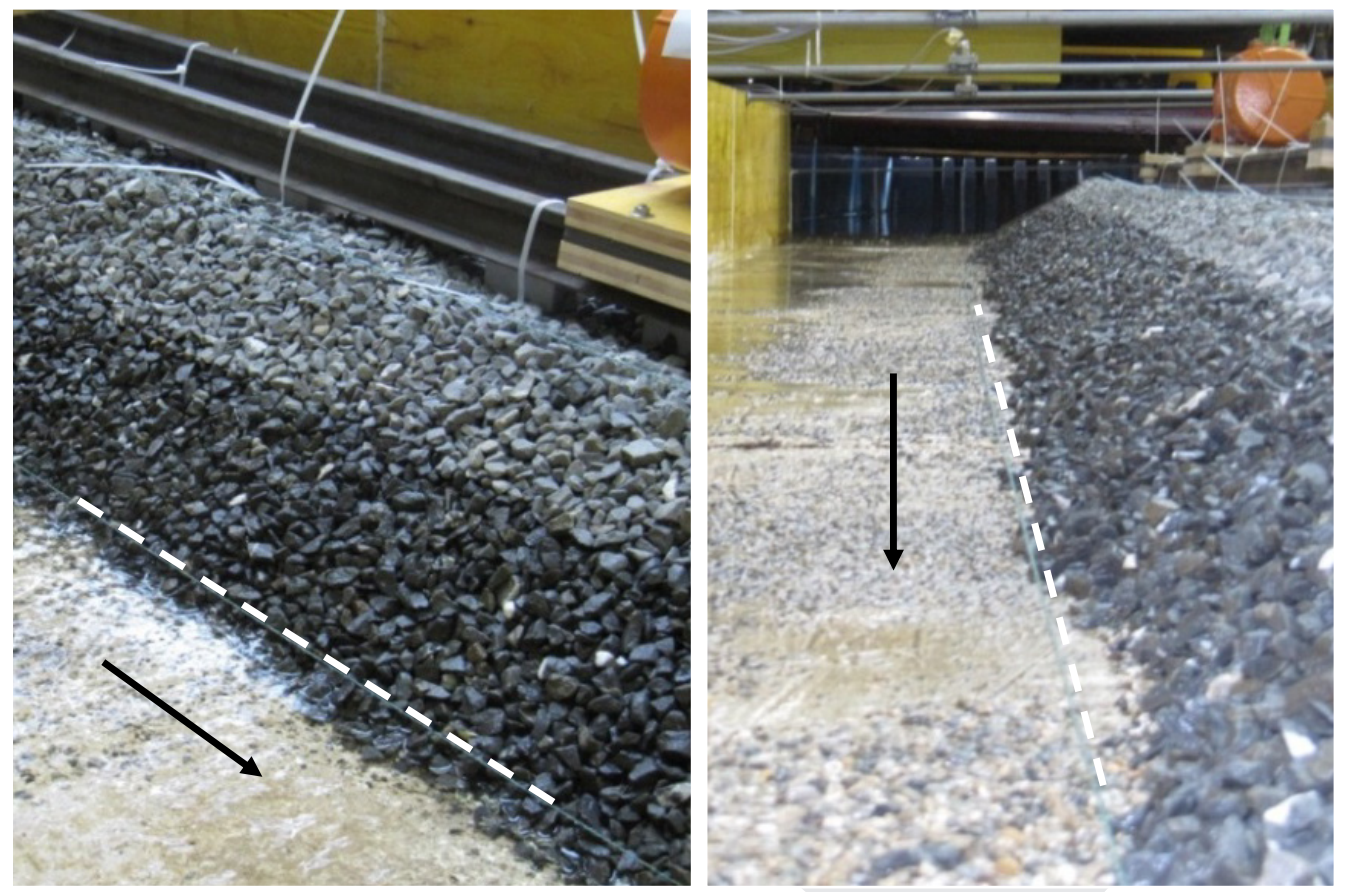

Figure 15: Final erosion of the bench for a slope of $0.65 \%$ and a specific discharge of $1.04 \mathrm{~m}^{2} / \mathrm{s}$ for the test without vibration (left) and for the test without vibrations (right)

Figure 16 shows the sediment transport on the model, highlighting that the vibrations affect the stability of the ballast only with a solid discharge overpassing the limit of $9.5-19 \mathrm{~kg} / \mathrm{min} / \mathrm{m}$. The vibrations have a bigger impact for the low slope. The quantity of transported particles is increased by $60 \%$ for the low slope $(0.65 \%)$ and $17 \%$ for steep slope $(3.0 \%)$.

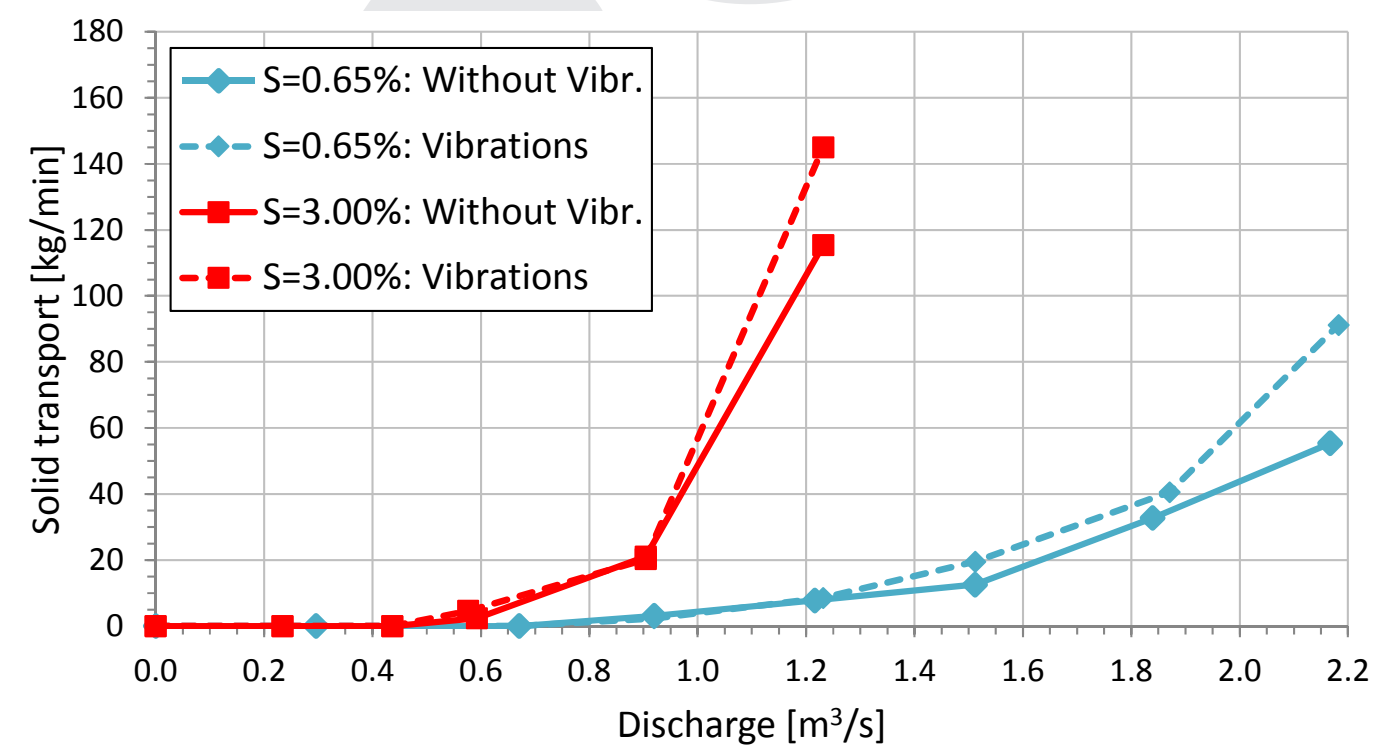

Figure 16: Specific solid discharge $(\mathrm{kg} / \mathrm{min} / \mathrm{m})$ related to specific liquid discharge $\left(\mathrm{m}^{2} / \mathrm{s}\right)$, for tests with and without obstacles, and without vibrations, for a slope of $0.65 \%$ and a slope of $3.0 \%$. 
If the ballast is already destabilised by a flood at its toe, the passage of a train over the track accelerates the destruction of the ballast layer. For low slopes, the increase of bed load transport can still not endanger the ballast.

\section{$4 \quad$ Numerical model for drainage system}

\subsection{Goals of the numerical model}

The tests on the physical model highlighted that the excess flow on the track may cause ballast erosion. Thus, the final objective of the study is to provide an optimised drainage system that conducts flow into the manholes. Different configurations are designed and their performance is investigated using a numerical model with the CFD solver Flow-3D. Only the flow around and in the manhole is considered and modelled in the numerical simulation. The simulations take into account neither a mobile bed nor erodible ballast. The tests are performed in clear water conditions. The simulations are performed at prototype scale. The goal of the numerical model is to provide a drainage system configuration, which reduces the risk of ballast entrainment by minimising the flow over the platform.

The software Flow-3D in its version 10.1 from Flow Science Inc. in New Mexico, USA (Flow Science, 2008) has been used. This software was successfully applied in the simulation of pressure flow, flow below gates, and free surface flow [4].

\subsection{Experimental setup and calibration}

Flow-3D numerically solves the continuity and momentum equations using finitevolume approximation. The flow region is subdivided into a mesh of fixed rectangular cells. With each cell, there are associated local average values of all dependent variables. All variables are located at the centre of the cells except for velocities, which are located at cell faces (staggered grid arrangement). The mesh is composed of more than one million cells, which dimensions vary from $2 \mathrm{~cm}$ along both the vertical direction and the flow direction, and $3 \mathrm{~cm}$ along the direction perpendicular to the flow. In order to evaluate how the flow behaves under different flow conditions, the discharge is increased from $0.05 \mathrm{~m}^{3} / \mathrm{s}$ to $2.0 \mathrm{~m}^{3} / \mathrm{s}$ by regular time steps. In the numerical model, the boundary conditions are defined as follows: lateral borders (along the flow direction) set as symmetries, upstream as inflow boundary with imposed water level varying over time following imposed discharge values, and downstream as outflow conditions. Curved obstacles, wall boundaries, or other geometric features are embedded in the mesh by defining the fractional face areas and fractional volumes of the cells that are open to flow. The Fractional AreaVolume Obstacle Representation (FAVOR ${ }^{\mathrm{TM}}$ ) method used exclusively in FLOW3D eliminates stair step effect that might otherwise occur with a simple Cartesian grid system by smoothly blocking out fractional portions of grid cell faces and volumes. Thus any real object face has to cross at least two grid cell boundaries to be rendered in the computational domain. The current time-level value is used to 
evaluate most terms in the equations of the local variables explicitly. In this way, a simple and efficient computational scheme is produced for most purposes. Nevertheless, it requires the use of a limited time-step size to maintain computationally stable and accurate results. The two-equation $(\mathrm{k}-\varepsilon)$ model is used as the turbulence model for the simulations.

The results obtained by Flow-3D have been validated by the acquired water lines from the physical model for the case of a single obstacle (i.e. manhole). The water depth plotted by numerical simulation effectively represents the conditions evaluated on the scale model. Moreover, the particular flow effect recorded on the physical model is reproduced by Flow-3D (Figure 17). The visual analysis and the comparison between hydraulic conditions on the physical and numerical models permit one to assure the validity of the latter.
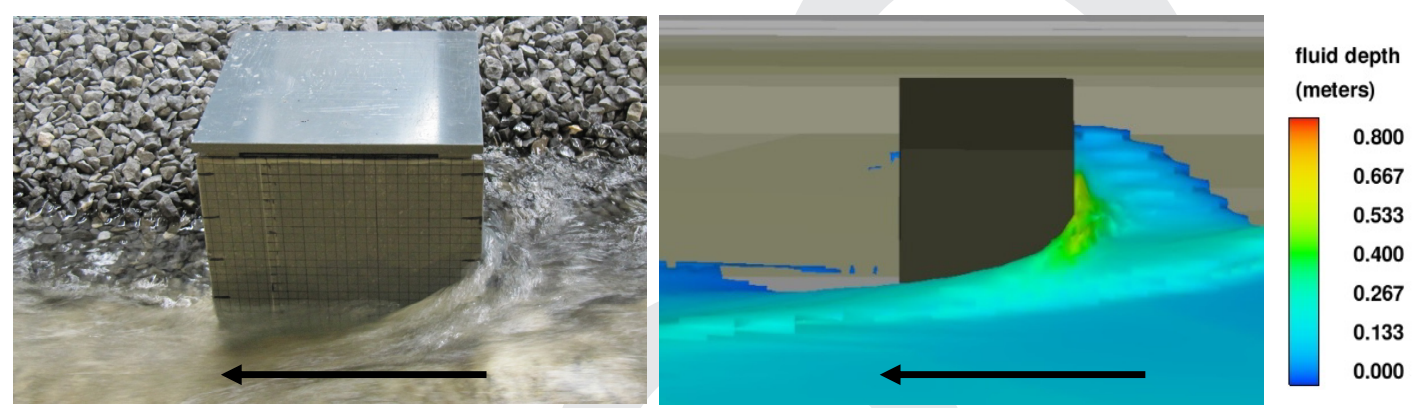

Figure 17: Results on physical model (left) and results on numerical model (right) with a longitudinal track slope of $2.5 \%$ and a specific discharge of $0.80 \mathrm{~m}^{2} / \mathrm{s}$

Once the numerical model has been validated, numerical test series' were performed using a different initial configuration. The manhole is modelled with increased dimension, from a square shape of $0.8 \mathrm{~m}$ per side to a rectangular shape of $1.0 \mathrm{~m} \mathrm{x}$ $1.2 \mathrm{~m}$ (Figure 18). Moreover, the manhole is aligned to the inner limit of the ballast toe, differing from the physical model position. The numerical simulations are performed considering varying discharges between $0.05 \mathrm{~m}^{3} / \mathrm{s}$ and $1.0 \mathrm{~m}^{3} / \mathrm{s}$. The slopes tested are $0.5 \%, 1.5 \%$ and $3.5 \%$.

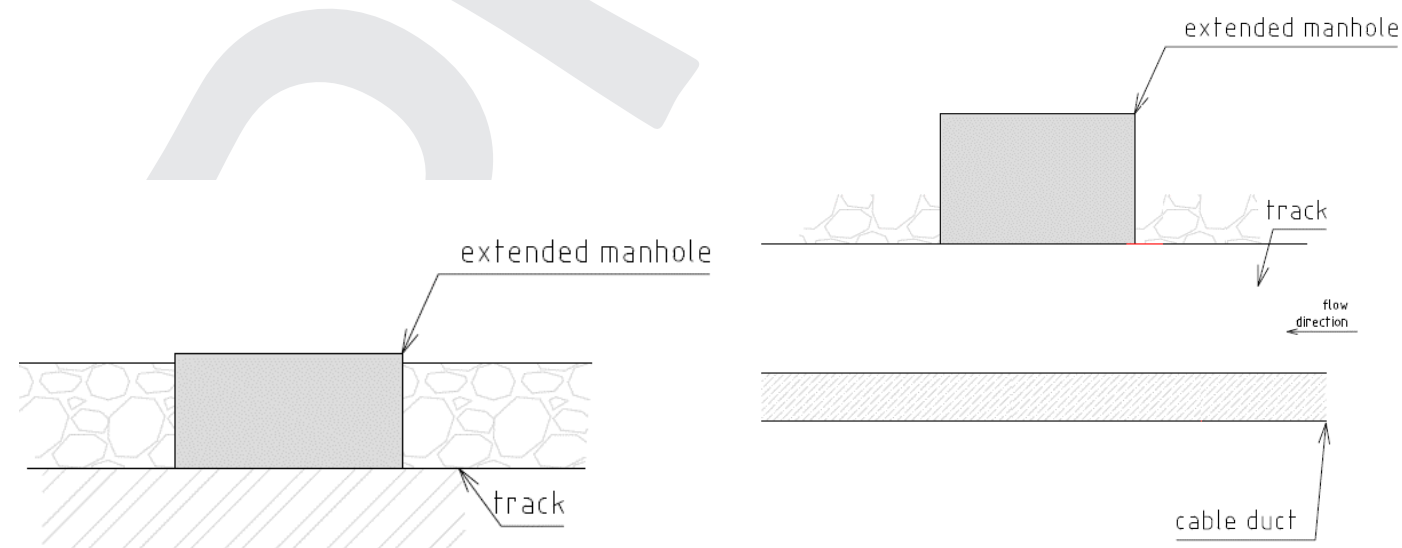

Figure 18: Manhole dimensions and position along the ballast. Lateral view (left) and top view (right) 
The outcomes of the numerical model permit one to measure the water depth and its velocity in the proximity of the obstacle. The water depth measurements are useful in evaluating the effectiveness of the drainage system configurations tested ( $c f$. 4.2.1).

\subsubsection{Drainage system configurations}

Since the "Sarry risk" is still possible, one of the objectives of this study is to provide an optimised configuration for the drainage system. The reduction of the amount of water flowing along the platform decreases the potential risk of ballast failure. Two preliminary drainage system configurations are created and performed using discharges varying from $0.05 \mathrm{~m}^{3} / \mathrm{s}$ to $2.0 \mathrm{~m}^{3} / \mathrm{s}$. Furthermore, three optimised geometries are proposed. In order to evaluate the efficiency of the tested configurations, the diverted discharge through the manhole is compared with the specific discharge from upstream.

The purpose of the drainage system is to maximise the quantity of water flowing along the platform into the manhole. The first configuration consists of a manhole combined with a gutter covered by a metal grid (Figure 19). The gutter is $0.3 \mathrm{~m}$ wide and $0.3 \mathrm{~m}$ deep, placed transversally to the flow direction. The grid has a mesh of $0.02 \mathrm{~m} \times 0.02 \mathrm{~m}$ and it was modelled with "baffles" in Flow-3D by impeding flow through a grid cell border to its neighbouring cell defined by a two-dimensional surface.

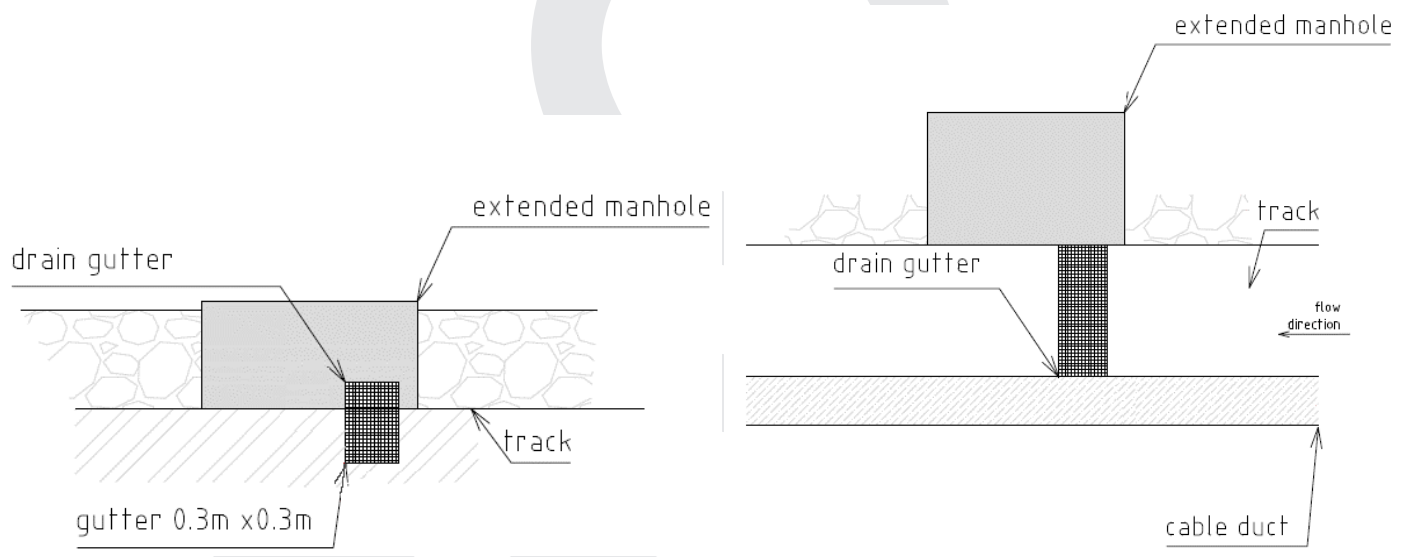

Figure 19: Gutter and upstream grid dimensions, position along the sewer manhole. Lateral view (left) and top view (right)

The outcomes of the first drainage system show a decreased water level downstream of the gutter. The lateral opening on the manhole is only partially covered by water.

For the low slope, almost all the flowing water is captured by the manhole. At the same time, the evacuated flow release is not enough for high discharge on the track.

The second configuration considers adding a sill downstream of the gutter, as shown in Figure 20. The sill is $0.2 \mathrm{~m}$ high, with a slope of $3 / 2$ (horizontal/vertical) and a length of $1.2 \mathrm{~m}$. The gutter and the grid have the same dimensions as the first configuration. 


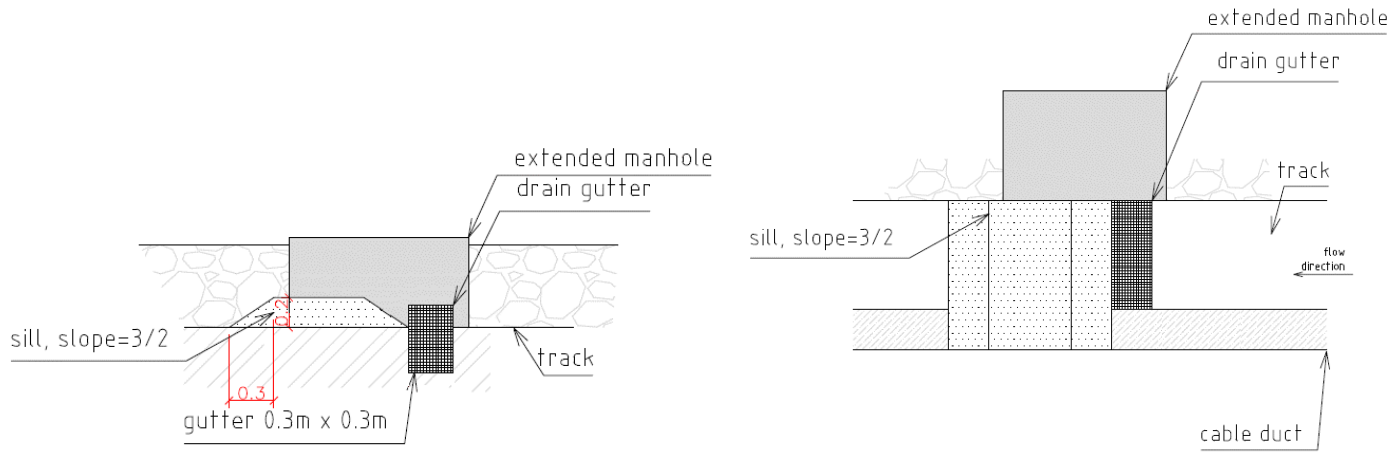

Figure 20: Dimensions of the $0.2 \mathrm{~m}$ high sill and position along the manhole. Lateral view (left) and top view (right)

The results show a different hydraulic behaviour created by the sill, which contributes to slowing down the water velocity reducing its transport capacity. The added sill contributes to stabilising the ballast around the obstacle and increases the manhole capacity, even for a high discharge (Figure 21).

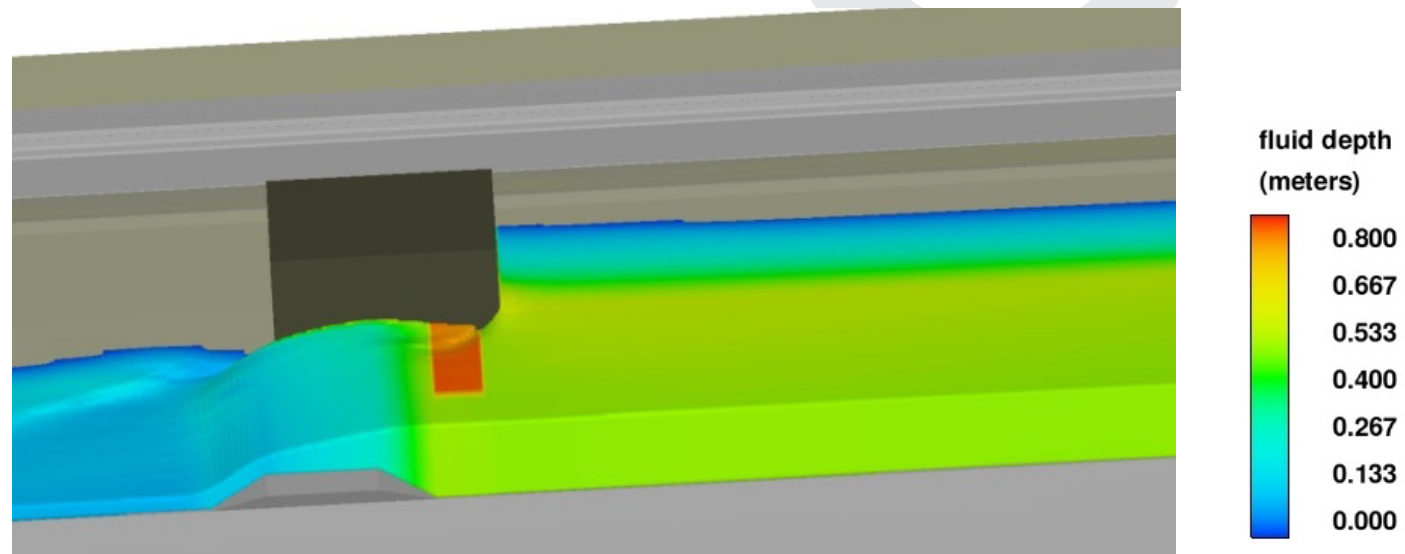

Figure 21: Water depth in the case of a sewer manhole with step downstream of 0.2 $\mathrm{m}$ high, with a slope of $0.5 \%$ and a specific discharge of $0.55 \mathrm{~m}^{2} / \mathrm{s}$

Conversely, it should be noticed that the reduced transport capacity does not prevent the possibility of gravel obstructing the grid.

The preliminary results show a potential for optimisation, allowing the evaluation of three optimised configurations.

\subsubsection{Optimised configurations}

Based on the preliminary results, the optimised configurations aim at increasing the flow rate drained by the manhole.

The first way to optimise the drainage capacity was to move the gutter downstream of the manhole (Figure 22). The second modified configuration evaluates the improving effect played by a gutter, placed downstream of the manhole, having reduced dimensions to $0.2 \mathrm{~m} \times 0.2 \mathrm{~m}$. Finally, the third optimised 
geometry proposes a reduced sill height to $0.1 \mathrm{~m}$, placed at the same position as the preliminary configuration.

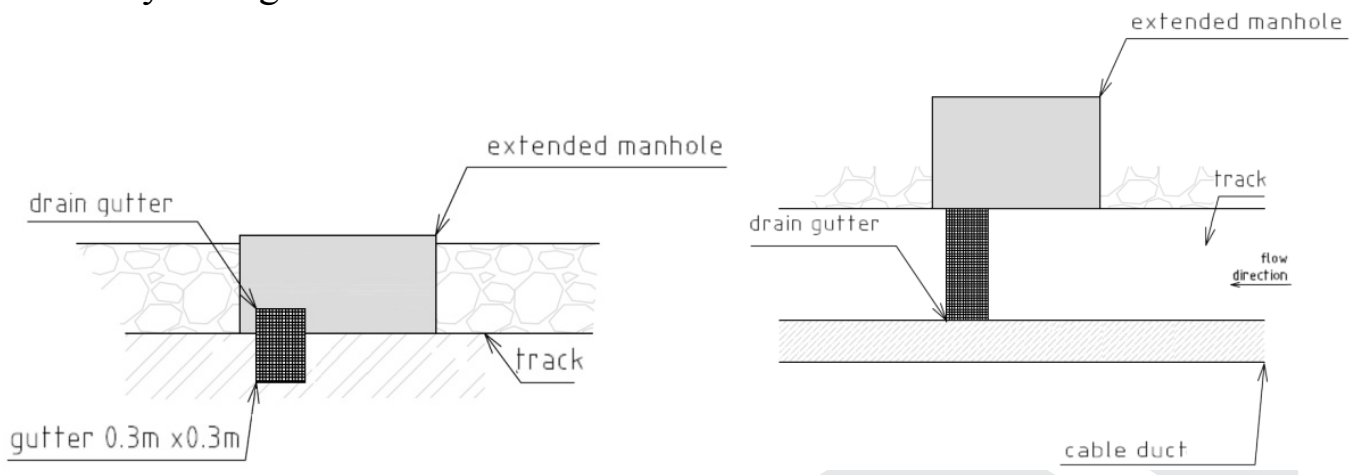

Figure 22: Dimensions of the gutter downstream and position along the manhole.

Lateral view (left) and top view (right)

\subsection{Comparison and discussion of the results}

Figure 23 compares the evacuated discharge as a function of the upstream discharge for the different tested configurations.

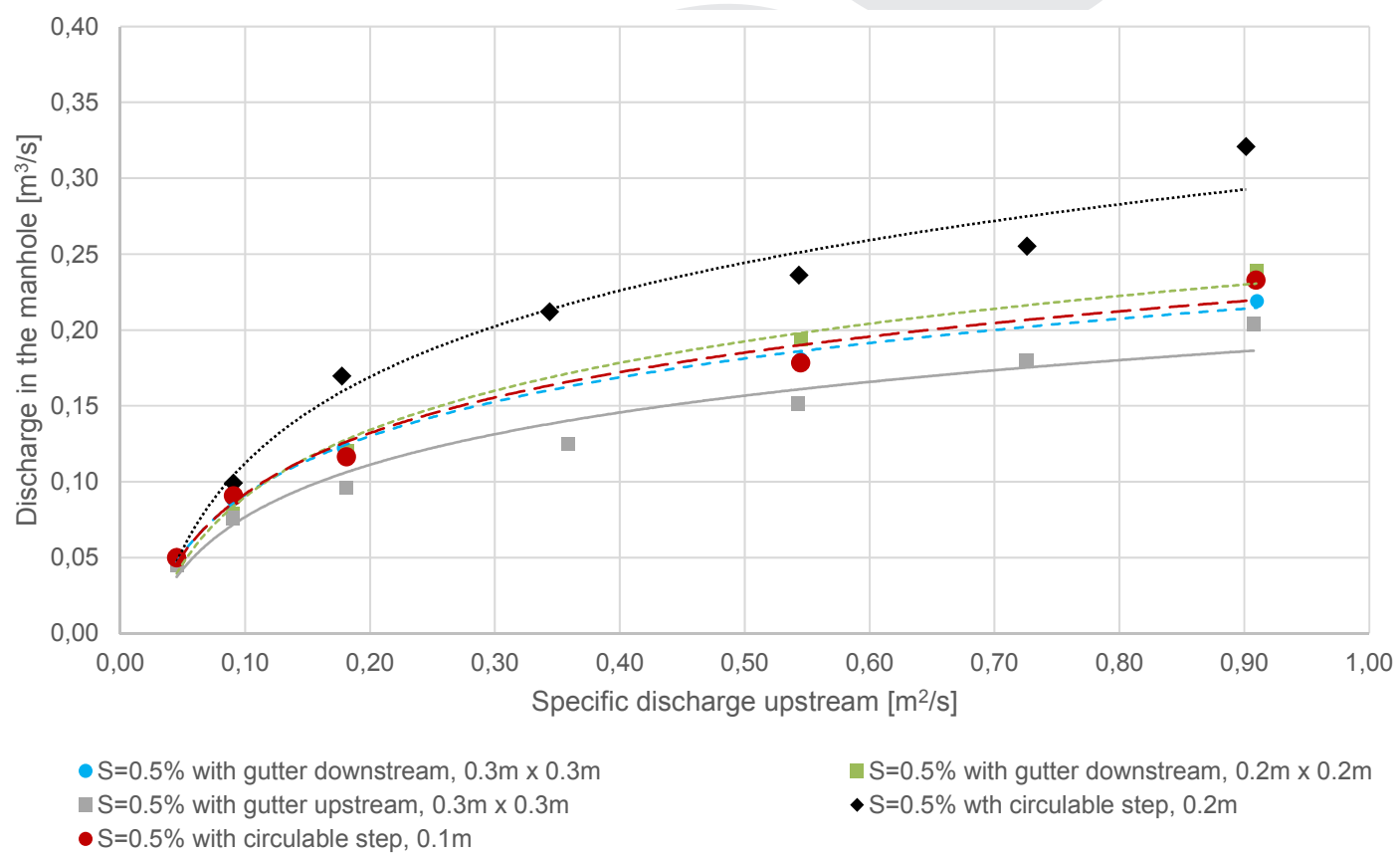

Figure 23: Comparison between the different tested configurations for a slope of $0.5 \%$

Independent from the slope, the optimal solution in order to divert water through the manhole consists in a $0.2 \mathrm{~m}$ high sill. On the other hand, the most ineffective configuration is the simple gutter with a large grid $(0.3 \mathrm{~m} \times 0.3 \mathrm{~m})$ placed upstream of the manhole for low slopes.

For the steep slopes, the most ineffective configuration is the gutter placed downstream of dimensions $0.2 \mathrm{~m} \times 0.2 \mathrm{~m}$. The weak performance of the latter 
configuration is as a result of the different hydraulic conditions with high flow velocities for the steep slope, and difficulty to penetrate inside the gutter.

The sill contributes to decelerate the flow velocity, but its presence can cause an accumulation of particles upstream of the sill and an increased derivation of solid material with the risk of blockage of the drainage system.

Figure 24 compares the specific discharge downstream of the manhole with the specific discharge upstream of the manhole considering the limits for the solid transport. The limit of linear transport is not reached. Through placing two manholes in proximity to each other, it could be possible to drastically reduce the flow along the track.

As a general conclusion, the most efficient solution is the manhole equipped with a $0.2 \mathrm{~m}$ high sill. In the event that this option is not available, for low slopes, it is suggested to install a gutter of $0.2 \mathrm{~m} \times 0.2 \mathrm{~m}$ dimensions in the downstream part of the manhole. For a steep track slope, a gutter of $0.3 \mathrm{~m} \times 0.3 \mathrm{~m}$ would be more efficient, because the hydraulic conditions do not allow smaller gutter dimensions.

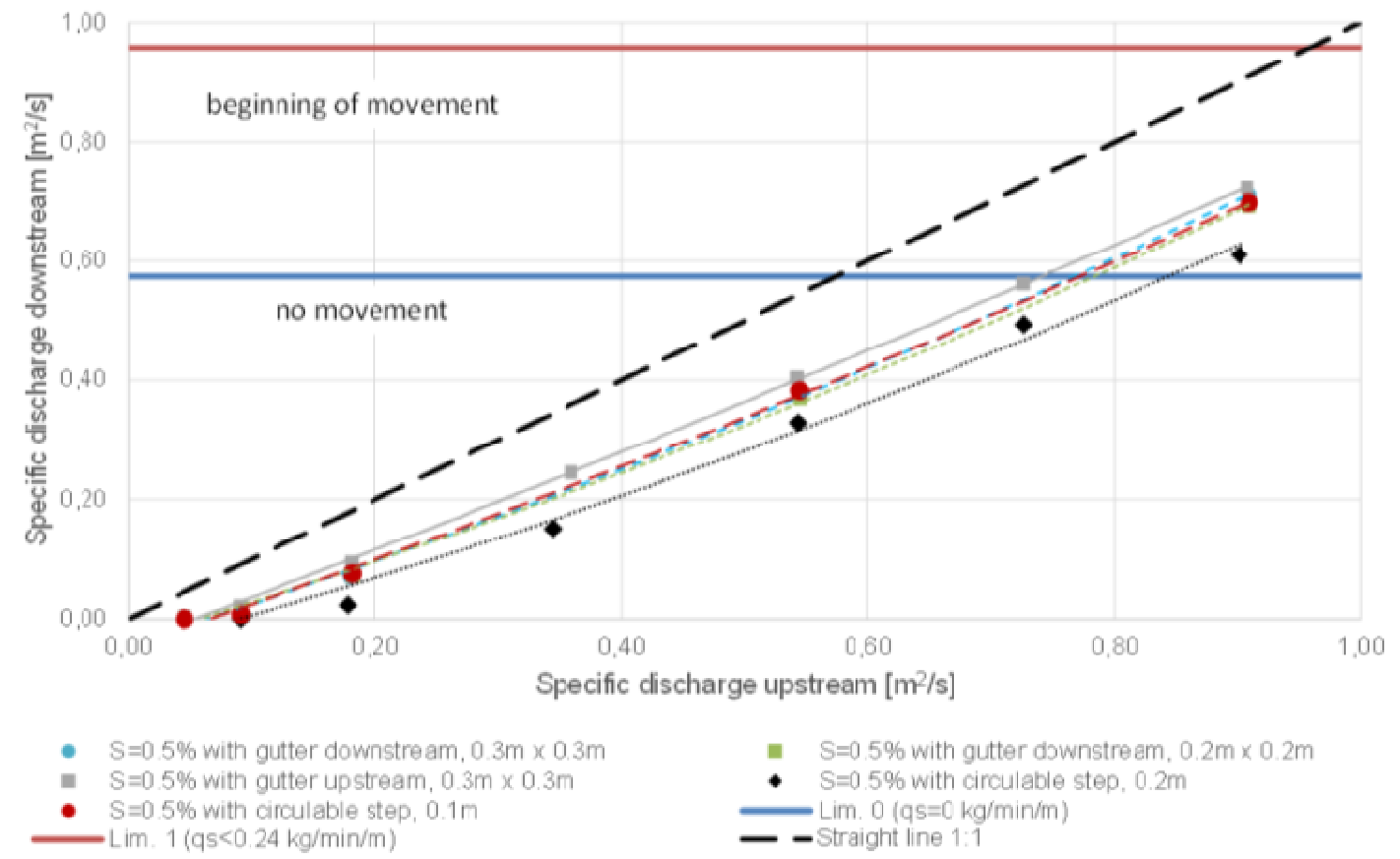

Figure 24: Discharge downstream a sewer manhole related to discharge upstream for every tested configurations for a slope of $0.5 \%$. Limits of solid transport for bench of ballast indicated on the figure

\section{Conclusion}

In order to manage the risk of ballast transport caused by the drainage system overflow on HSLs, research was undertaken by the SNCF in collaboration with EPFL to study the phenomenon on both physical and numerical models. 
Among other purposes, this research aims at identifying and quantifying the flow conditions, in terms of water depth and velocity, that results in the ballast removal and transportation. Systematic tests were conducted for ballast transport in normal and severe conditions. The test series without obstacles permitted one to identify three thresholds for ballast transport (initiation of transport, linear transport, and intense ballast transport) considering flow depth, flow velocity, and track slope.

The above mentioned flow characteristics have become the main criteria now used in the determination of the railway risk.

The results provided by the tests show that the presence of obstacles (e.g. catenary pole, bridge abutments, and manholes) on the platform increases the risk of ballast transport. In terms of ballast toe destabilisation, the worst case occurs with a bridge abutment that should locally protect against erosion. Considering that in a real case a succession of obstacles is often possible along the railway, the interaction between two obstacles was investigated. The test performed confirmed the stabilising effect of the manhole when placed downstream from the other obstacle. When the obstacles are located close to each other, the propagation of the erosion process is reduced. With an increasing distance, the ballast particles are much more likely to be transported by the flow. The tests performed with vibration highlighted that it may accentuate the beginning of the mobilisation of ballast particles, but without significantly damaging the ballast stability.

The risk associated with the ballast erosion has motivated the authors to perform a series of numerical simulations in order to provide an optimised configuration for the drainage system. The numerical model, created with the CFD solver Flow-3D, permits assessing the performance of different drainage systems configurations serving to direct the excess flow to manholes. The results show the important role played by the slope. Different solutions should be taken into account considering the track slope. In the case of a steep slope, a sill of $0.2 \mathrm{~m}$ height placed beside the manhole results in the optimal solution. On the other hand, when the track has a low slope, the presence of a gutter downstream of the manhole helps in reducing the flooding of the platform.

This research project has highlighted the vulnerability of railway infrastructure in the case of an overflow. Tests on both physical and numerical models helped in understanding the phenomenon of ballast transport, permitting one to provide general recommendations for further constructions and for improving the existing railway infrastructure. Further analysis should be performed for evaluating the influence of moving sediment in relation to the drainage system.

Based on the physical experiments, it was possible to define new criteria to identify the "Sarry risk". Moreover, the experiments supplied useful information on the zones of ballast track that should be stabilised in order to avoid erosion in the case of extreme events.

\section{References}

[1] D. C. Froehlich, Sizing loose rock riprap to protect stream banks. River Res. Applic., 29: 219-235. doi: 10.1002/rra.1587, 2013. 
[2] M. Jafarnejad, M. J. Franca, M. Pfister, A.J. Schleiss, Time Dependent Failure Analysis of Compressed Riprap as Riverbank Protection. 35th IAHR World Congress, Chengdu, China, 9-13 September 2013.

[3] M.A. Stevens, D.B. Simons, G.L. Lewis, Safety Factors for Riprap Protection. ASCE Journal of the Hydraulics Division 102(HY5): 637-655, 1976.

[4] R. Gabl, B. Gems, M. Aufleger, G. De Cesare. Anregungen zur Qualitätssicherung in der 3-D-numerischen Modellierung mit FLOW-3D [Contribution to quality standards for 3D-Numerical Simulations with FLOW3D]. WasserWirtschaft, (3): 15-20, 2014.

[5] J. Perlet, Les aménagements hydrauliques de la Ligne TGV Méditerrannée, Revue Générale des Chemins de Fer, 103., 2002.

[6] D. Nivon, C. Pams Capoccioni, "Analyse du risque hydraulique sur lignes à grande vitesse exploitées”, Symposium international Géorail, 1, 749-755, 2011.

[7] C. Pams Capoccioni, D. Nivon, L.G. Chenot, "Les crues à grande vitesse" Revue Générale des Chemins de Fer, 221 : 100-106, 2012.

[8] C. Pams Capoccioni, D. Nivon, J. Amblard, G. De Cesare, T. Ghilardi, "Analyse de risques pour les circulations ferroviaires d'un débordement de drainage sur ligne à grande vitesse (LGV)", SHF Congress "Evénements extrêmes d'inondation 2013", 2013.

[9] C. Pams Capoccioni, D. Nivon, J. Amblard, G. De Cesare, T. Ghilardi, M. Jafarnejad, "Analysis of the risks for rail traffic in the event of overflowing of the drainage system on high speed lines (HSL)", 10th World Congress on Railway Research, Paris, France, 2013.

[10] V.T. Chow. Open channel flow. MacGraw-Hill Book Co. Inc.: New York, 1959.

[11] Jr., W. Viessman, G. L. Lewis, Introduction to hydrology, Fourth Edition, Harper Collins, pp $311 \mathrm{ff} ., 1995$.

[12] A.J. Schleiss, W.H. Hager, Constructions hydrauliques, Ecoulements stationnaires, Traité de Génie Civil de l'Ecole Polytechnique Fédérale de Lausanne, PPUR, Lausanne, 614pp., 2009.

[13] M.S. Yalin, A.M. Da Silva, Fluvial processes - Monograph, IAHR, Delft, ISBN: 90-805649-2-3, 197pp., 2001.

[14] LCH, Impact sur le Ballast des Eaux de Ruissellement (IBER), Etude sur modèle physique, Rapport d'étude LCH N 13/2011, unpublished, 2011.

[15] P. Novak, V. Guinot, A. Jeffrey, D.E. Reeve, Hydraulic modelling - an introduction: principles, methods and applications, Spon Press: Oxon, ISBN 978-0-419-25010-7, 599 pp., 2010.

[16] M. S. Yalin, Theory of hydraulic models (Vol. 266). The Macmillan Press: London, 266pp., 1971.

[17] V. Bodin. Comportement du ballast des voies ferrées soumises à un chargement vertical et latéral. Thèse Ecole des Ponts, Paris. 2001.

[18] LCH, Impact sur le Ballast des Eaux de Ruissellement (IBER2), essais complémentaires, Rapport d'étude LCH N 13/2013, unpublished, 2014. 